\title{
Pharmaco-immunomodulatory interventions for averting cytokine storm-linked disease severity in SARS-CoV-2 infection
}

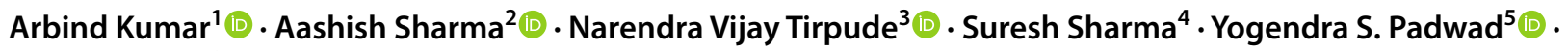 \\ Sanjay Kumar ${ }^{6}$ D
}

Received: 22 September 2021 / Accepted: 24 November 2021 / Published online: 20 January 2022

(c) The Author(s), under exclusive licence to Springer Nature Switzerland AG 2021

\begin{abstract}
The year 2020 is characterised by the COVID-19 pandemic that has quelled more than half a million lives in recent months. We are still coping with the negative repercussions of COVID-19 pandemic in 2021, in which the 2nd wave in India resulted in a high fatality rate. Regardless of emergency vaccine approvals and subsequent meteoric global vaccination drives in some countries, hospitalisations for COVID-19 will continue to occur due to the propensity of mutation in SARS-CoV-2 virus. The immune response plays a vital role in the control and resolution of infectious diseases. However, an impaired immune response is responsible for the severity of the respiratory distress in many diseases. The severe COVID-19 infection persuaded cytokine storm that has been linked with acute respiratory distress syndrome (ARDS), culminates into vital organ failures and eventual death. Thus, safe and effective therapeutics to treat hospitalised patients remains a significant unmet clinical need. In that state, any clue of possible treatments, which save patients life, can be treasured for this time point. Many cohorts and clinical trial studies demonstrated that timely administration of immunomodulatory drugs on severe COVID-19 patients may mitigate the disease severity, hospital stay and mortality. This article addresses the severity and risk factors of hypercytokinemia in COVID-19 patients, with special emphasis on prospective immunomodulatory therapies.
\end{abstract}

Keywords COVID-19 $\cdot$ ARDS $\cdot$ Cytokines syndrome $\cdot$ Immune modulators $\cdot$ Therapeutics

\section{Introduction}

In March 2020, the World Health Organisation (WHO) declared the COVID-19 outbreak a global public health emergency. Consequently, COVID-19 waves further

Arbind Kumar

arbind.tripathi01@gmail.com; surya_prbha@ymail.com

Sanjay Kumar

sanjaykumar@ihbt.res.in

Aashish Sharma

aashishsharmaoct11@gmail.com

Narendra Vijay Tirpude

narendra@ihbt.res.in

Suresh Sharma

sureshmicrobiologist8948@gmail.com

Yogendra S. Padwad

yogendra@ihbt.res.in

1 COVID-19 Testing facility, CSIR-Institute of Himalayan

Bioresource Technology (IHBT), Palampur,

Himachal Pradesh, India deteriorated situation causing persistent state of fear. This catastrophic situation created immediate need of therapeutics or vaccines resulting in emergency approval for prophylaxis and treatment of COVID-19. However, emergence of SARS-CoV-2 variants prompted concerns about the efficacy

2 COVID-19 Testing facility, CSIR-Institute of Himalayan Bioresource Technology (IHBT), Palampur, Himachal Pradesh, India

3 Animal Facility, CSIR-Institute of Himalayan Bioresource Technology (IHBT), Palampur, Himachal Pradesh, India

4 COVID-19 Testing facility, CSIR-Institute of Himalayan Bioresource Technology (IHBT), Palampur, Himachal Pradesh, India

5 Dietetics and Nutrition Technology Division, CSIR-Institute of Himalayan Bioresource Technology (IHBT), Palampur, Himachal Pradesh, India

6 CSIR-Institute of Himalayan Bioresource Technology (IHBT), Palampur, Himachal Pradesh, India 
and sensitivity of approved medicines and vaccines, which are, regrettably, still hazy. In March-April, 2021, India faced a massive surge of COVID-19 cases and deaths, and was the world's leading country in terms of infection rate. Since inception of pandemic, many suggestions and speculations were made to spot possible cure for this disease. Various drug entities showed promising clinical results, but only a small percentage of these are approved and moved forward to phase trials (Rohilla 2020; Kumar et al., 2021). Majority of these drugs were targeted to counteract inflammatory aggravation during pathologic progression of COVID-19. Hypercytokinemia is an uncontrolled hyper-inflammatory reaction that occurs when a localised inflammatory response to a viral or bacterial infection spreads across the body. Endothelial dysfunction, vascular damage, and paracrine/metabolic dysregulation are all caused by dysregulated high cytokine levels, which eventually harm many vital organ systems (Leisman et al., 2020; Ye et al., 2020; Bhaskar et al., 2020; Fodor et al., 2021). The innate immune response is the first host anti-viral response against invading viruses, which triggers the release of type I/III interferon (IFNs), pro-inflammatory cytokines like TNF- $\alpha$ and interleukins like IL-1, IL-6, and IL-18. These cytokines and interleukins induce collective effect on the target cells and potentiate the adaptive immune response. However, dysregulated immune response is one of the cogent reasons of mortality associated with COVID-19, known as cytokines explosion or storm, which is represented by excessive secretion of cytokines such as, IL-2, IL-6, IL-7, IL-10, IP-10 (interferon-gamma-inducible protein), MCP-1 (monocyte chemoattractant protein), TNF- $\alpha$ and MIP- $1 \alpha$ (macrophage-inflammatory protein), GM-CSF in human body and such patients are in strict need of ICUs (intensive care units) (Costela-Ruiz et al., 2020; Ragab et al., 2020; Khadke et al., 2020). Despite many critics raising concern about the excessive immune response or cytokine storm during the pathogenesis of COVID-19, there are several studies highlighting that lymphopenia and pneumonia are the critical immune dysregulation developed during the severe cases of COVID-19, which characterises the higher plasma levels of pro-inflammatory cytokines(Bhaskar et al., 2020; Ye et al., 2020; Fara et al., 2020). Two different autopsy reports demonstrated that the damage to vital organs was not associated with viral inclusion of the respective organs. It could be linked to severe immune injury, caused by cytokine storm, instead of direct viral damage (Xu et al., 2020a, b; Yao et al., 2021). In severe cases, cytokine storms harm healthy cells, first the lungs, and potentially spreading to other vital organs like the heart, brain, and kidney. Some studies highlighted that increased amount of pro-inflammatory cytokines in serum (e.g. IL-1, IL-6, IL-12, IFN-, IP-10, MCP-1, MIP-1, TNF- $\alpha$, and GCSF), was correlated with pulmonary inflammation and acute respiratory distress syndrome in affected patients (Chen et al., 2020).
The extent of the severity of the disease is directly proportional to the cytokine storm (Cingolani et al., 2020), which often leads to multi-organ failure and death. Numerous retrospective studies of cytokine blockade such as IL-6, IL1-, JAK, NF-KB, GM-CSF inhibitors have shown promising results (Fara et al., 2020; Ragab et al., 2020; Ye et al., 2020). Several clinical trials are underway or recently completed, and the results are eagerly expected. Regardless of speedy vaccination drives and uptake in many countries, hospitalisations with clinical severity of COVID-19 are still being reported. It might be due to the propensity of mutation and virus evasion from protection that occurs through natural immunological selection (Thompson et al., 2021). Timely therapeutic intervention in patients with hyper-inflammation could prevent the illness from progressing to ARDS and eliminate the need for invasive ventilation. To our knowledge, there have not been any updated reviews shedding light on the effectiveness of immunomodulatory therapy to combat COVID-19 severity. This review enlightened the implications and risk factor of hypercytokinemia/cytokine storm for COVID-19 patients, with special emphasis on potential therapeutic strategies used to mitigate COVID-19 severity.

\section{Risk factor associated with COVID-CSS (cytokine storm syndrome)}

During a pandemic, COVID-19 disease is diagnosed through testing and most infections are self-limiting or mild forms, which can be recovered through standard operating procedures, but as the disease progresses and develops severe pneumonia, it becomes more difficult for clinicians to operate. Establishing ARDS during disease progression could be one of the leading causes of death. As estimated, 50 and 65\% deaths were associated with ARDS and severe COVID19 during early phase of the pandemic (Bhatraju et al., 2020). The probability of fatality or death with COVID-19 is greatly impacted by age and prior comorbidities. Older patients over 65, as well as those with chronic comorbidities such as cardiovascular disease, diabetes, hypertension, and respiratory illness, are far more vulnerable to severe or fatal disease outcomes. But, it is uncertain to determine the time of a patient's death in COVID-19, which is linked with preexisting health conditions (Streeck et al., 2020; Bartlett et al., 2020). Low arterial oxygen concentrations, alveolar damage, and a dysregulated inflammatory response in the lungs are all symptoms of COVID-19 ARDS (Matthay et al., 2019). An earlier report stated that COVID-19 ARDS was caused by a "cytokine storm," which refers to severely ill COVID19 patients having significantly higher levels of circulating inflammatory cytokine levels than those with mild disease or healthy controls (Mehta et al., 2020a, b; Blanco-Melo, 2020; Giamarellos-Bourboulis et al., 2020). Hypercytokinemia, 
better described as a cytokine storm, massive release of many inflammatory cytokines in serum was determined in COVID-CSS (cytokine storm syndrome). Surprisingly, in many patients with severe COVID-19 disease, the serum IL-6 level was markedly elevated at around 100-1000 pg/ $\mathrm{ml}$ (Blanco-Melo et al., 2020; Herold et al., 2020; Laing et al., 2020). This magnitude of elevated IL-6 levels in COVID-CSS is comparable to severe CART-cell CRS and higher than that of other hyper-IL-6 syndromes, including multicentric Castleman disease, where elevated IL-6 levels are noted beyond $100 \mathrm{pg} / \mathrm{ml}$ (England et al., 2021; van Rhee et al., 2014). In COVID-CSS, the foundation of immune dysregulation was correlated with the common terminal hyperinflammatory pathway that is characterised by markedly elevated IL-6, severe T-cell lymphopenia, and respiratory failure (Laing et al., 2020; Giamarellos-Bourboulis et al., 2020; Lucas et al., 2020; Coomes and Haghbayan, 2020). Among the elevated cytokines, IL-6 is primarily involved in pro-inflammatory activation during cytokine-mediated organ dysfunction and tissue damage (Crayne et al., 2019) and IL6-directed therapy acts as the cornerstone of cytokine-based therapy (Hoiland et al., 2020; Kotch et al., 2019; Chen et al., 2019). Some studies demonstrated that IL- $6>80 \mathrm{pg} / \mathrm{m} 1$ along with high C-reactive protein $>97 \mathrm{mg} / \mathrm{l}$ point towards probable respiratory failure and are specific in predicting death (Herold et al., 2020; Laguna-Goya et al., 2020). Stukas et al., 2020 reported IL-6 to be inversely proportional to the ratio of arterial oxygen tension and fraction of inspired oxygen $(\mathrm{PaO} 2 / \mathrm{FiO} 2)$ and static lung compliance (Stukas et al., 2020). IL-6 blockade with tocilizumab resulted in partial restoration of these immune defects (Giamarellos-Bourboulis et al., 2020; Mazzoni et al., 2020). In addition to IL-6, IL-12 (p40), MIP-1a, and MIP-1b are critical chemokines, accountable for the recruitment of activated immune cells to the site of infection (Schulz et al., 2016; Coper et al., 2007; Menten et al., 2002). The hematopoietic growth factor, GM-CSF (Granulocyte-macrophage colony-stimulating factor), is also a key immunological modulator. Upon receiving immunological stimuli, it is released by many cell types such as $\mathrm{T}$ cells, macrophages, endothelial cells, and fibroblasts, and it can control key cytokines that can drive both innate and adaptive immune responses (Hamilton, 2000). Other elevated inflammatory indicators such as $\mathrm{C}$-reactive protein are substantially linked to IL-6 plasma levels in CSS with COVID-19 (Liu et al., 2020). Various studies have demonstrated high levels of high-sensitivity C-reactive protein (Hs-CRP) in the serum levels of severe COVID-19 patients. Persistently high levels of CRP are a sign of ongoing chronic inflammation and it is a key inflammatory indicator linked to increased risks of death and organ damage (Clyne \& Olshaker, 1999; Schmidt-Arras \& Rose-John, 2016; Sharifpour et al., 2020). Elevated CRP levels have been linked to disease severity and predictions in many viral respiratory infections such as SARS, MERS-CoV, and H1N1 (Ko et al., 2016; Vasileva \& Badawi, 2019; Wang et al., 2004). CRP level assessment has recently been one of the major indicators for detecting COVID-19 disease severity. The major complication associated with COVID-19 disease is cytokine storm, and it is a leading cause of multiple organ failure and ARDS. As a result, effectively repressing the cytokine storm is critical for preventing severe COVID-19 consequences and lowering mortality (Fig. 1). Numerous efforts have been made throughout the world to assess the severity of the situation in real time and apply potential therapeutics to save patients' lives. Many immunomodulatory medicines have been used off-label as COVID-19 treatments in hospitalised patients based on preclinical results, but further evidence in the context of clinical practise is needed. Many repurposed drugs have been utilised and suggested for clinical studies, and a few drugs are showing promising outcomes.

\section{Tocilizumab (IL-6 inhibitor)}

Tocilizumab is a recombinant humanised monoclonal antibody that has been approved for use in the treatment of cytokine release syndrome. It is particularly effective in inhibiting IL- 6 production. The dysregulated host immune response is reported in the severe case of COVID-19, which has a propensity to release excessive amounts of cytokines, resulting in a cytokine storm or pulmonary inflammation (Bhaskar et al. 2020; Ye et al., 2020). Among all the cytokines, IL-6 is predominately produced and can be an ideal target to circumvent COVID-CSS. Based on that, Tocilizumab, a monoclonal antibody inhibitor of IL-6, can be used to ameliorate the intense inflammatory response associated with severe COVID-19, and thus improve clinical outcomes. Various clinical studies have been showing promising results in COVID-19 treatment (Kumar et al., 2021) (Table 1). Xu et al. 2020a, b were the first to test tocilizumab's efficacy on 21 severe or critical COVID-19 patients. Clinical data indicated that symptoms, hypooxygenemia, and CT opacity changes improved quickly after tocilizumab treatment in the majority of patients, indicating that tocilizumab might be an effective COVID-19 treatment. This observation has prompted many clinical trial studies on tocilizumab. A few studies contradicted the efficacy of tocilizumab, and no significant clinical improvements were achieved through the administration of tocilizumab. But these trials have limitations like the inclusion of small numbers of patients, less severely ill patients, and the exclusion of critically ill patients (Stone et al., 2020; Hermine et al., 2021). The study by many research groups suggested that TCZ may lower the frequency of ICU hospitalisations and/or fatalities in patients with severe COVID-19 (Alattar et al., 2020; Commes and Haghbayan, 2020). Gupta et al., 2021, conducted a multicentre cohort study, enrolling 4485 


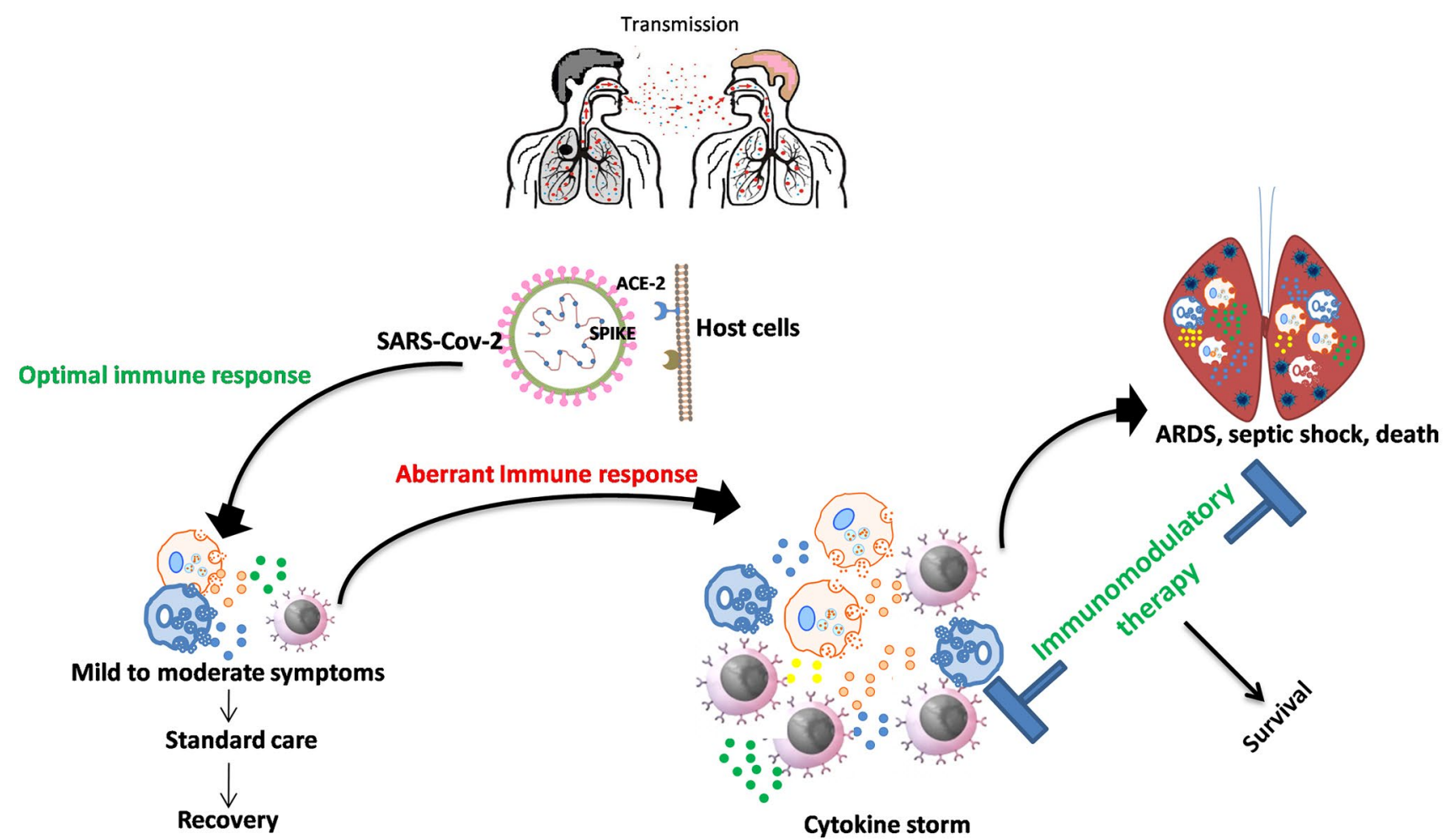

Fig.1 Schematic representation of the pathological progression of COVID-19 towards ARDS and possible reinforcement of immunomodulatory therapy to combat COVID-CSS

critically ill COVID-19 patients. After 27 days of therapy, individuals who received tocilizumab had a reduced risk of mortality than those who did not receive tocilizumab. The anticipated 30 -day mortality was $27.5 \%$ in the tocilizumabtreated patients and $37.1 \%$ in the control groups (risk difference, $9.6 \%$ ). In this investigation, patients who received tocilizumab in the first two days of ICU admission had a decreased risk of in-hospital mortality than patients who did not get tocilizumab in the first two days of ICU admission (Gupta et al., 2021). Gordon et al., 2021 conducted a large randomised, embedded, multifactorial adaptive platform trial for community acquired pneumonia (REMAP$\mathrm{CAP}$ ) and included a total of 803 patients. Among them, 353 patients were assigned to tocilizumab to examine the efficacy of tocilizumab on survival and organ support in critically ill patients with COVID-19, and the outcome showed a survival benefit over the current standard of care, which included corticosteroids (Gordon et al., 2021). Guillén et al., 2020 investigated the efficacy of tocilizumab in 64 hospitalised COVID-19 patients. After receiving tocilizumab, 49 patients (76.6\%) demonstrated an early positive response. There were no deaths or recurrences of illness. There were no more bacterial infections as a result of the treatment during the hospitalisation. However, patients who responded well to TCZ were younger in age (Gullein et al., 2020).

\section{Sarilumab}

Sarilumab is completely a human MCA (monoclonal antibody) responsible for inhibiting the binding of IL-6 and its own $\alpha$ receptor. Sarilumab is approved by FDA (Food and drug administration) for its use against the treatment of ankylosing spondylitis and arthritis rheumatoid (severe and moderate) (Khiali et al., 2020). As it inhibits both membrane bound and soluble form of IL-6 and possibly suppresses the pro-inflammatory signalling by immune cells as well as pulmonary-epithelial cells; its use can be possibly predicted in reducing the pulmonary complications raised due to COVID-19, along with respiratory failure (Lescure et al., 2021). Sarilumab suppresses the growth of Calu3 (human lung cancer cell line) and binds with high affinity to epitope of IL-6R, thereby blocks both the activation (trans and cis) of IL-6 signalling (Yousefi et al., 2021). It is considered to be a safe and well-tolerated drug with recommended dosage not exceeding $200 \mathrm{mg}$ every fortnight (Khiali et al., 2020; León López et al., 2020).

Various studies have been conducted by various researchers to check the efficacy and safety of sarilumab in patients suffering from rheumatoid arthritis (Table 2). A study done by (Bae and Lee, 2017) with four randomised controlled trials with 2667 patients suffering from rheumatoid arthritis 


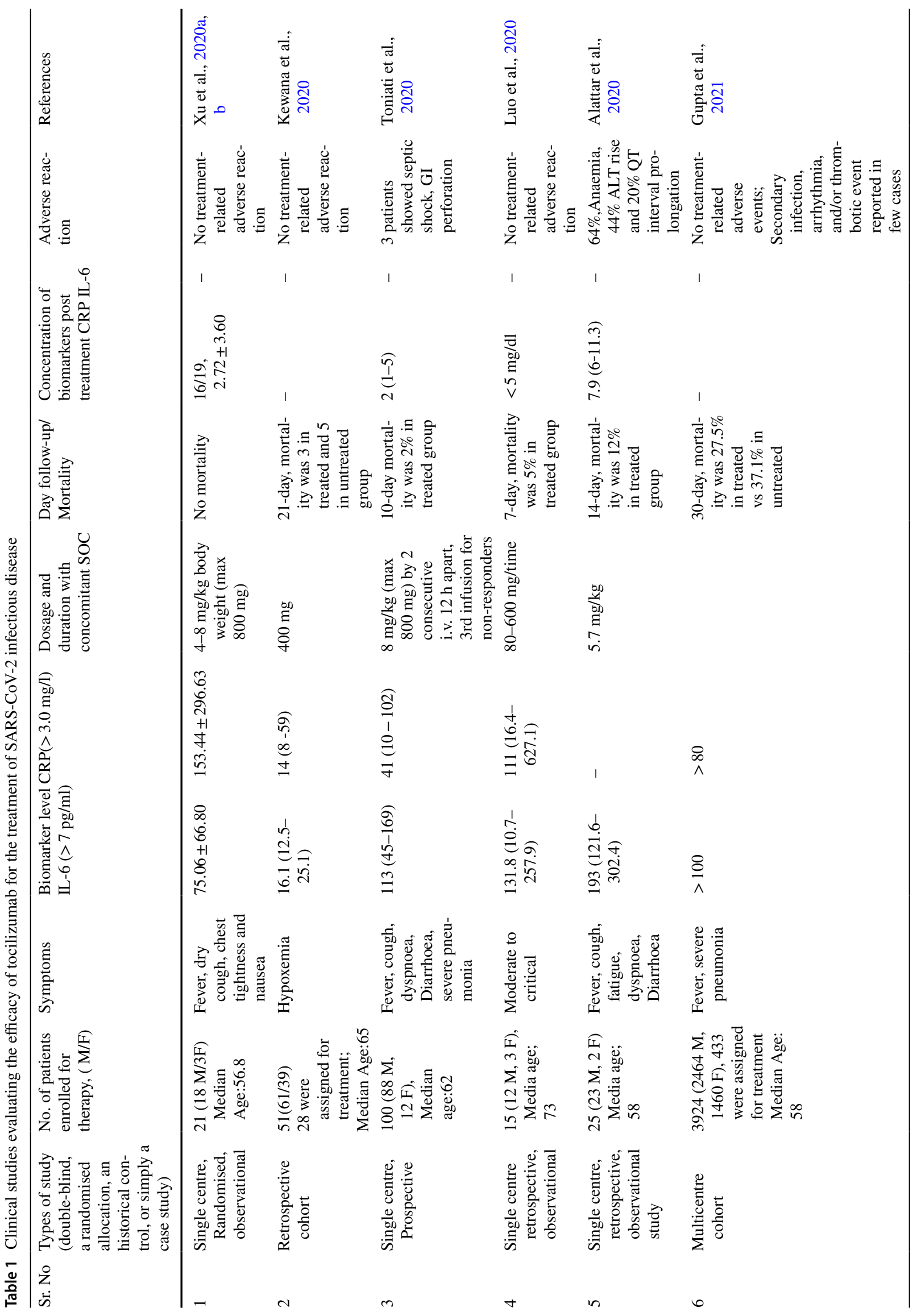




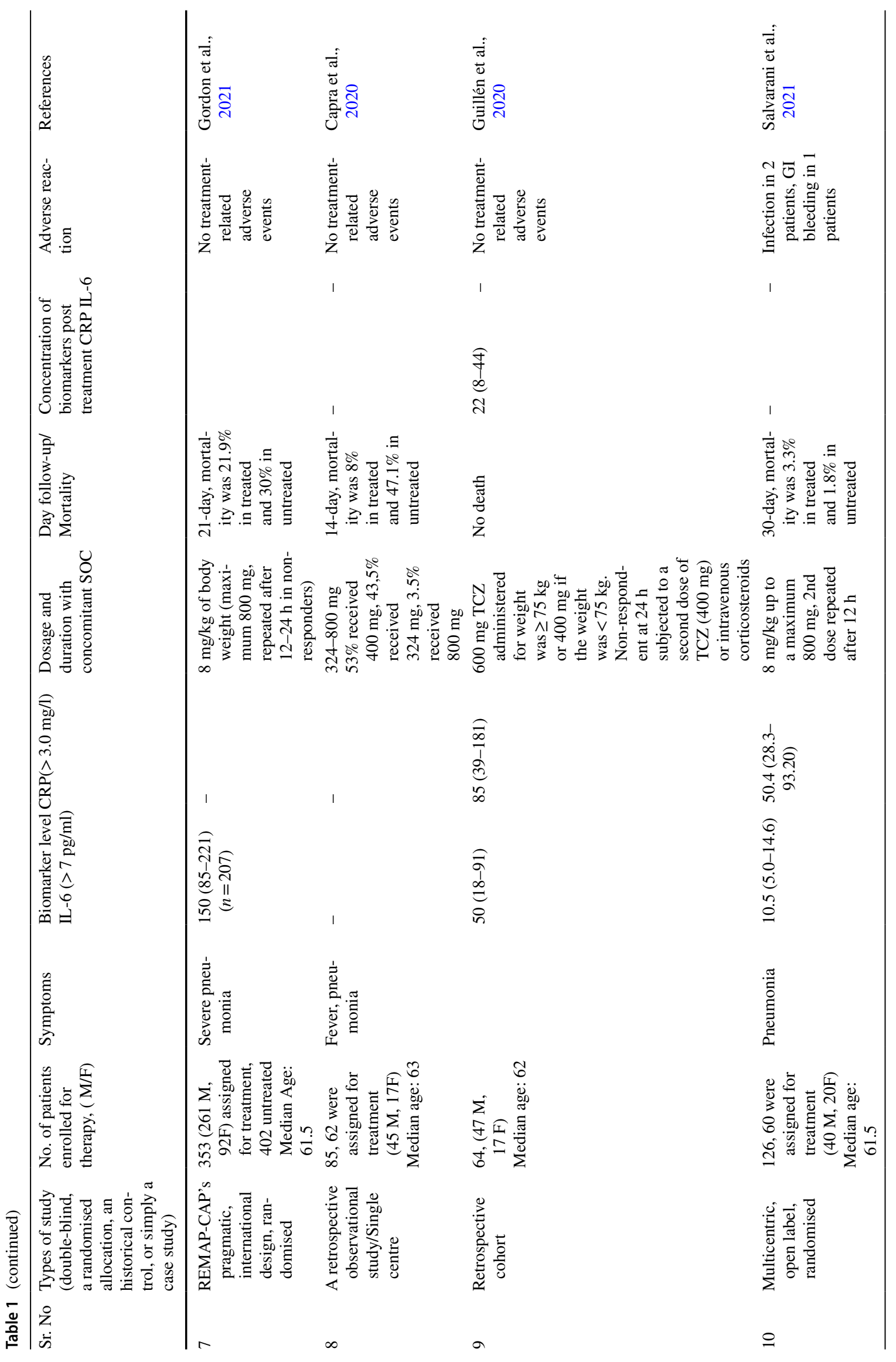




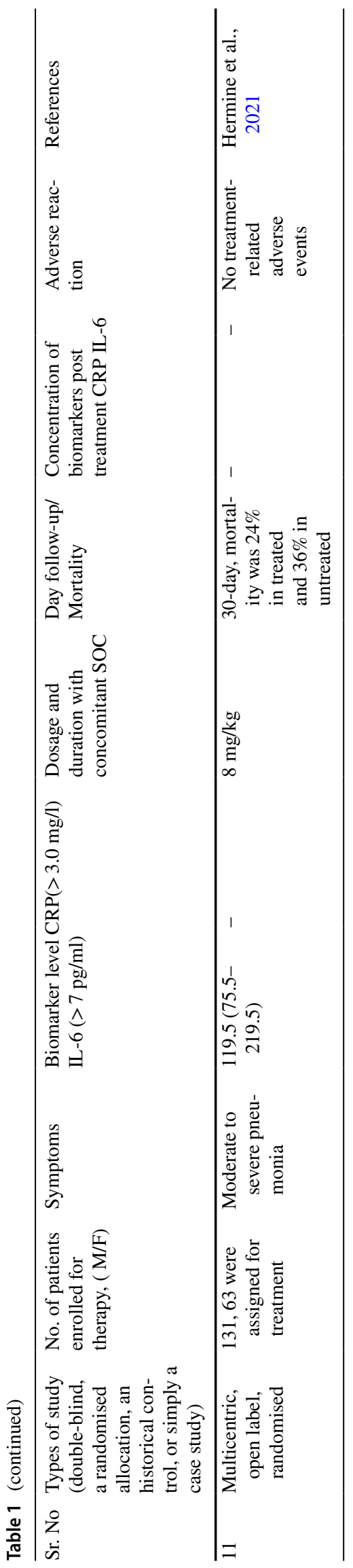

showed that Sarilumab at $150 \mathrm{mg}$ and $200 \mathrm{mg}$ is effective as well as tolerated among the patients. The adverse event rate of Sarilumab is very low, which is around 6.7-9.4 per 100 patients per year (Khiali et al., 2020).

In a study conducted by (Benucci et al., 2020) over 8 patients ( 6 males and 2 females, mean age 62 years) with confirmed positive PCR (polymerase chain reaction) reports, the patients were given sarilumab $(400 \mathrm{mg})$ along with standard therapy of hydroxychloroquinone $(400 \mathrm{mg})$, darunavir $(800 \mathrm{mg})$, enoxaparin $(100 \mathrm{U} / \mathrm{kg})$, and azithromycin $(500 \mathrm{mg})$. The study revealed that there was improvement of oxygenation and the oxygen requirement was reduced by $30 \%$. Seven patients showed progressive and significant reduction in echo score and improvement of Horovitz index was observed significantly (Benucci et al., 2020). Within 14 days, 7 of the 8 patients were tested negative and discharged from the hospital, while an 83-year-old patient showed no improvement.

Another study done by (Benucci et al., 2020) on COVIDpositive hospitalised patients $(\mathrm{n}=8, \mathrm{t}=14$ days $)$, three doses were given viz. first dose $(400 \mathrm{mg})$ after the first day of hospitalisation; second dose (200 mg) after 2 days and third dose $(200 \mathrm{mg}$ ) after 4 days. Other standard treatments were also carried out alongside such as azithromycin, cobicistat, HCQ, darunavir and enoxaparin. The result showed significant improvement in the count of lymphocytes, CRP and echo score. Gremese et al., 2020 conducted open-label observational study on 53 patients suffering from COVID19 with severe pneumonia. The patients were given 1-2 doses of sarilumab $(400 \mathrm{mg})$ in 1-11-day intervals along with LPV/r, HCQ, DRV/r, GC and heparin azithromycin. The result showed significant improvement in $89.7 \%$ of the patients who were not admitted in ICU. After the treatment, oxygen therapy was not required by $85.7 \%$ of the patients, while $64.2 \%$ of the patients admitted in ICU no longer require the intensive care and was shifted to normal wards.

There are limited data available addressing the use of sarilumab in the case of COVID-19 and various clinical trials are still in progress. Overall, it can be concluded from the limited published evidences that sarilumab can be used in treatment of COVID-19 (moderate to severe cases). However, further research is still required to explore the efficacy and safety of Sarilumab in treatment of COVID-19 (Khiali et al., 2020). Della-Torre et al., in 2020, conducted an open-label cohort study and check the efficacy of sarilumab in severe COVID-19 pneumonia patients. Fifty-six patients ( $\mathrm{PaO} 2 / \mathrm{FiO} 2<300 \mathrm{~mm} \mathrm{Hg}$ with hyper-inflammation) were enrolled and given sarilumab therapy. Twenty-eight patients received $400 \mathrm{mg}$ sarilumab intravenously in addition to standard of care, while rest 28 patients treated with standard of care alone. Sarilumab treatment resulted in clinical improvements in patients and they showed faster recovery. In patients with lung consolidation $<17$ percent at CT scan, the 


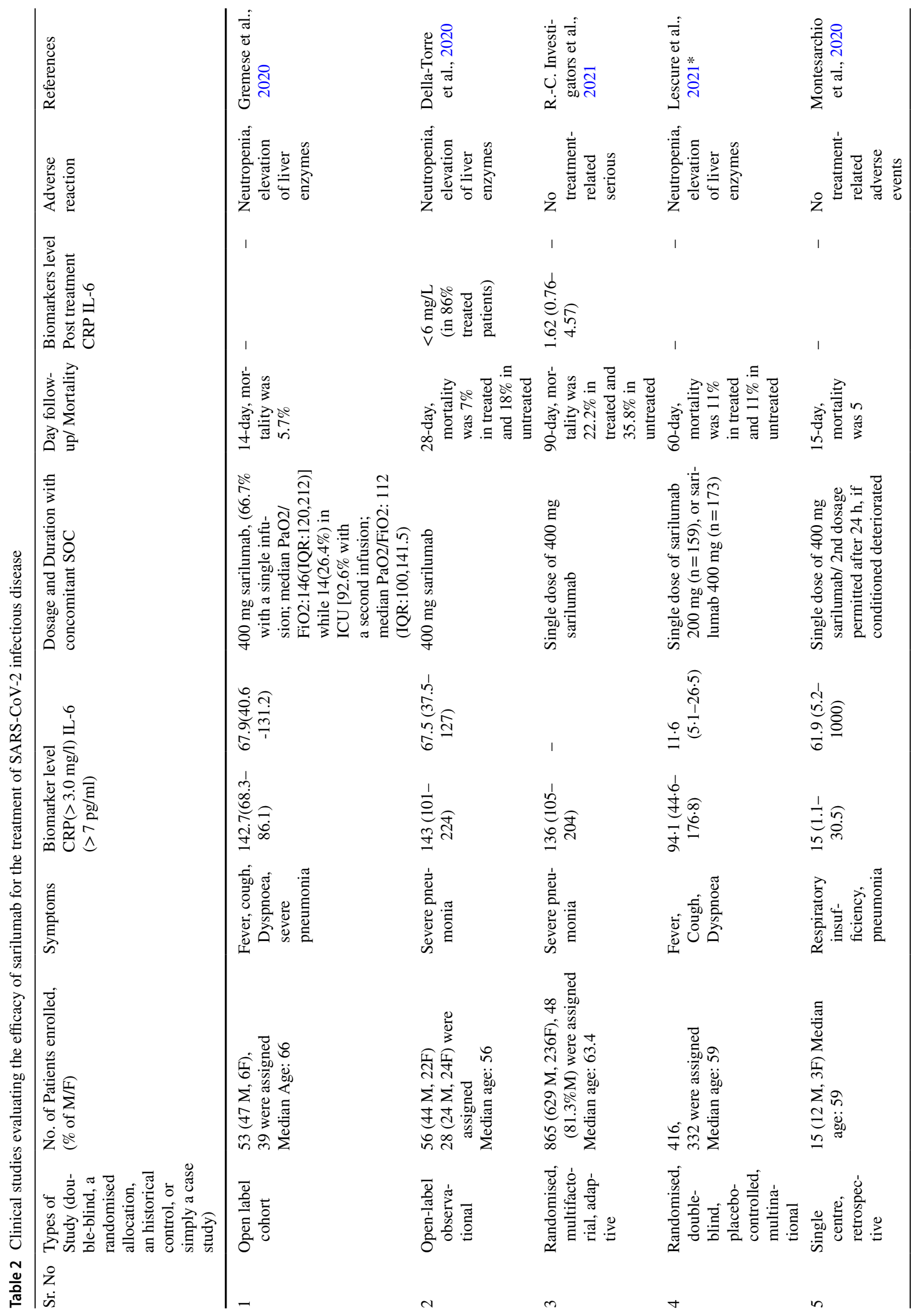




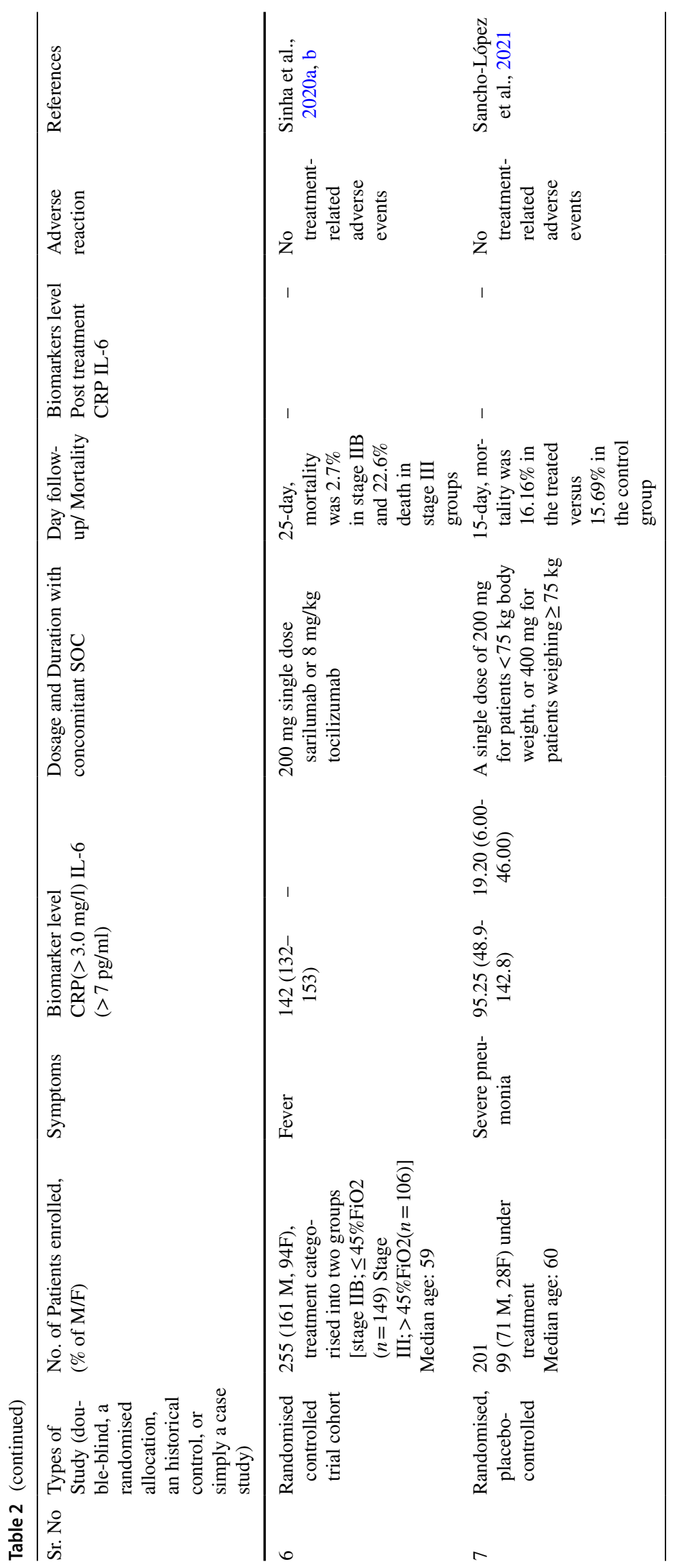


median time to clinical improvement following sarilumab was 10 days, compared to 24 days with standard therapy $(p=0.01)$. At day 28 of follow-up, the survival rate of sarilumab group was $93 \%$, compared to $82 \%$ standard treatment; however, the difference was statistically not significant (HR 0.36 ; $95 \%$ CI $0.08-1.68 ; p=0.21)$. But, patients with moderate pulmonary congestion healed quicker in the sarilumab therapy group (Della-Torre et al., 2020). In line with this study, Della-Torre et al., in 2021, conducted a study to assess the effectiveness of anti-cytokine therapies on COVID-19 patients with severe pneumonia and hyper-inflammation ( $\mathrm{PaO} 2 / \mathrm{FiO} 2$ ratio $300 \mathrm{mmHg}$ with hyper-inflammation). The patients were given $5 \mathrm{mg} / \mathrm{kg}$ anakinra twice daily until clinical improvements were not obtained. A single dose of tocilizumab (400 mg) was administered and repeated every $24 \mathrm{~h}$ if the condition worsened. A single dose of $400 \mathrm{mg}$ sarilumab was administered intravenously and the clinical outcomes were monitored and compared with standard care. The study included 107 patients treated with cytokine inhibitors and 103 patients treated with standard of care. Treatment resulted in a significantly greater survival rate compared to standard therapy in patients with $\mathrm{PaO} 2 / \mathrm{FiO} 2 \geq 100 \mathrm{mmHg}$ after a median of 106 days of follow-up (range 3-186) (p $0.001)$. Interestingly, anakinra also decreased mortality in patients with $\mathrm{PaO} 2 / \mathrm{FiO} 2<100 \mathrm{mmHg}(p=0.04)$ (DellaTorre et al., 2021). Studies suggested that the inhibition of IL-1 and Il-6 elevated response resulted in better survival rate, when treatment started early and before the establishment of ARDS.

\section{Anakinra}

Anakinra, a well-known IL-1 receptor antagonist, is used for the treatment of various hyper-inflammatory conditions like Still's disease, juvenile idiopathic arthritis, familial Mediterranean fever, etc. Anakinra is found to be super effective in treating cytokine storm syndrome including cytokine release syndrome as well as macrophage activation syndrome (Filocamo et al., 2020; Cavalli et al., 2020). It is approved by US-FDA (United States Food and Drug administration) for its use in the treatment of arthritis rheumatoid and multiinflammatory diseases (Navarro et al., 2020). It is known to possess the ability to block the activity of pro-inflammatory cytokines (IL- $1 \beta$ and IL- $1 \alpha$ ). As previously discussed, patients with COVID-19 disease exhibit hyper-inflammatory symptoms similar to cytokine storm and the release of interferon, IL-18, IL-6 and IL-1 $\beta$ in patients with macrophage activation syndrome. These disorders can be prevented up to great extent using agents that block the cytokines. Anakinra is one such blocking agent that is found to be effective in the treatment of these diseases. The use of anakinra permits the prompt discontinuation due to its short half-life, and thus considered suitable to be used in the case of critical patients.
Also, the anakinra is considered much safer as compared to other cytokine-blocking agents (Cavalli et al., 2020). Higher dosage of anakinra is recommended for patients suffering from heavy load of viral infection as in case of H1N1, Ebola and EBV (Filocamo et al., 2020). Anakinra tends to lower the death rate in patients having sepsis, liver dysfunction and disseminated-intravascular coagulation. Due to its short halflife and its property of inhibiting both the IL-1 subtypes, it could possibly be a promising treatment to cure severe COVID-19. A number of studies have been reported showing the beneficial effects of anakinra during initial treatment in patients suffering from COVID-19 disease (Aomar-Millán et al., 2021; Navarro-Millán et al., 2020) (Table 3).

A study was conducted by (Aomar-Millán et al., 2021) on 143 patients suffering from moderate hyper-inflammation and severe COVID pneumonia with the aim to depict the effect of anakinra on COVID patients. The patients were given standard therapy and were divided into 3 groups. Group 1 received pulses of methyl prednisolone, group 2 received tocilizumab in addition to methyl prednisolone and group 3 received anakinra as per the protocol. The first dose of anakinra was decided as per the weight of the patients. Patients with weight ranging from 50 to $60 \mathrm{~kg}$ were given dosage of $100 \mathrm{mg} / 12 \mathrm{~h} ; 60$ to $75 \mathrm{~kg}$ were given $100 \mathrm{mg} / 8 \mathrm{~h}$ and those above $75 \mathrm{~kg}$ were given $100 \mathrm{mg} /$ $6 \mathrm{~h}$. All patients received a dosage of $100 \mathrm{mg} / 12 \mathrm{~h}$ from the second day onwards till day 6 . The study lasted for 60 days. The results indicated that patients from group 3 who were receiving the dose of anakinra were associated with a lower risk of death rate. Also, the mean CD-4 count was reduced in group 3 after 3 days of the treatment. It was observed that none of the patients developed any complications after treatment with anakinra, and it was tolerated well among all the patients.

Another study conducted by (Navarro-Millán et al., 2020), on patients suffering from SARS CoV-2 with high fever and acute-hypoxemic respiratory failure (AHR failure). Out of 14 patients, 11 received anakinra treatment (100 mg every $6 \mathrm{~h}$, subcutaneously) for maximum 19 days. Seven patients with AHR failure did not require mechanical ventilation anymore after anakinra treatment of $\leq 36 \mathrm{~h}$ and were discharged from the hospital. While the other 3 patients who did not received the anakinra treatment needed mechanical ventilation. The study suggested that the use of anakinra could prove to be beneficial for treating patients suffering from COVID-19 with cytokine storm syndrome. Various other studies are available and are still in queue to evaluate the efficacy and safety of anakinra in COVID-19 patients. (Cavalli et al., 2020), they have administrated high dose $(5 \mathrm{mg} / \mathrm{kg}$, twice daily, intravenously) and observed the positive outcome, which showed improved respiratory function among the patients. No adverse events were observed. 


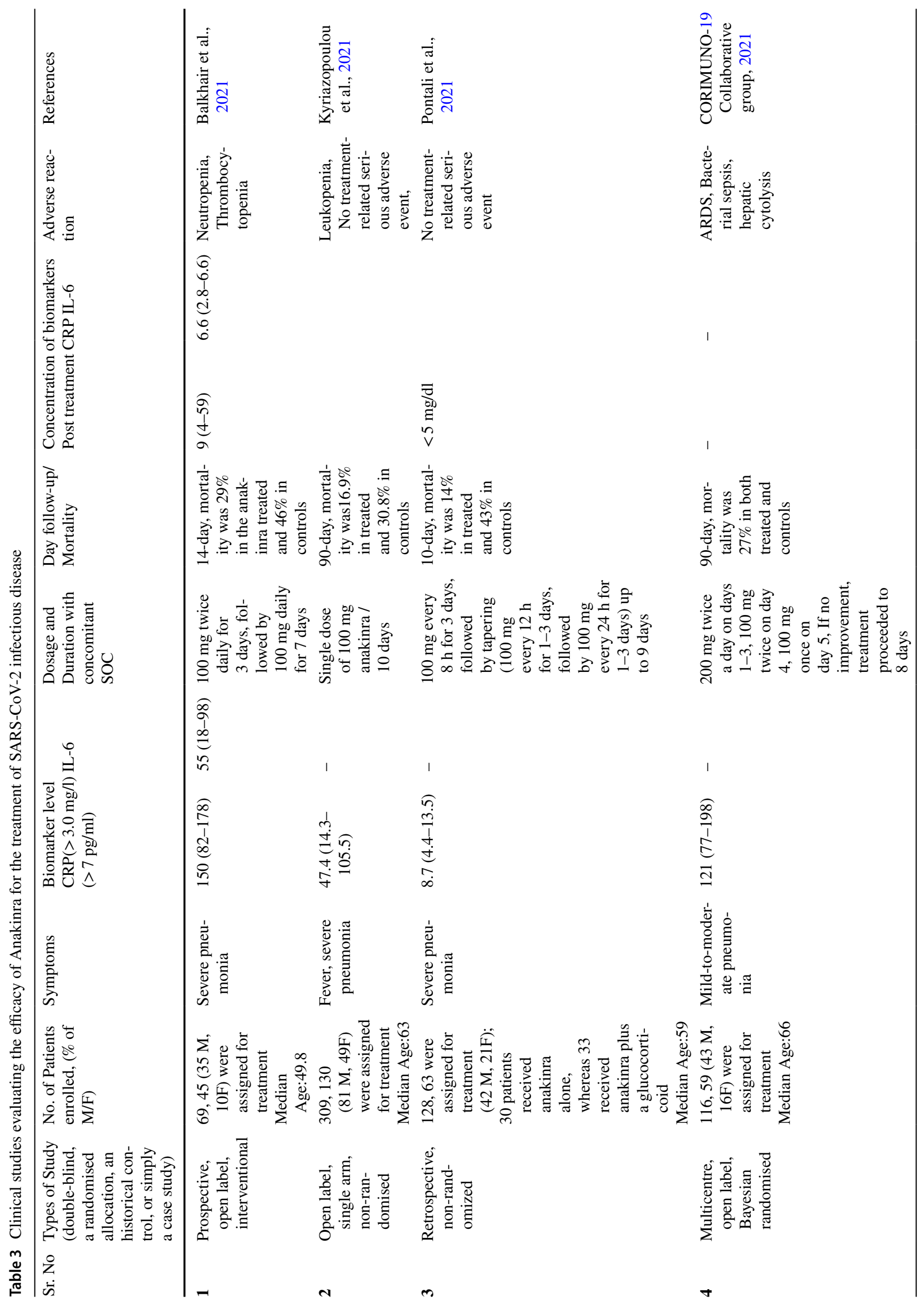




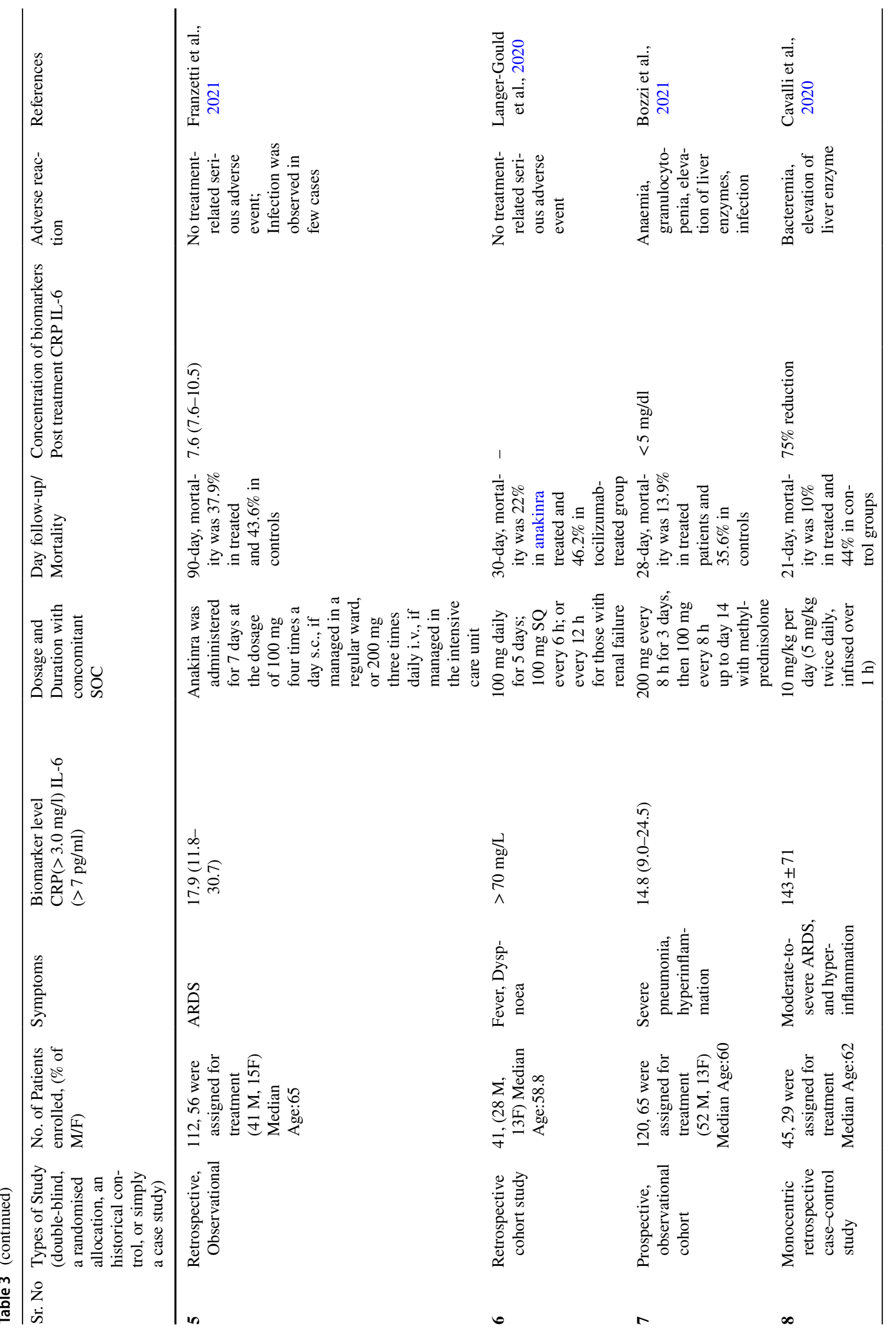




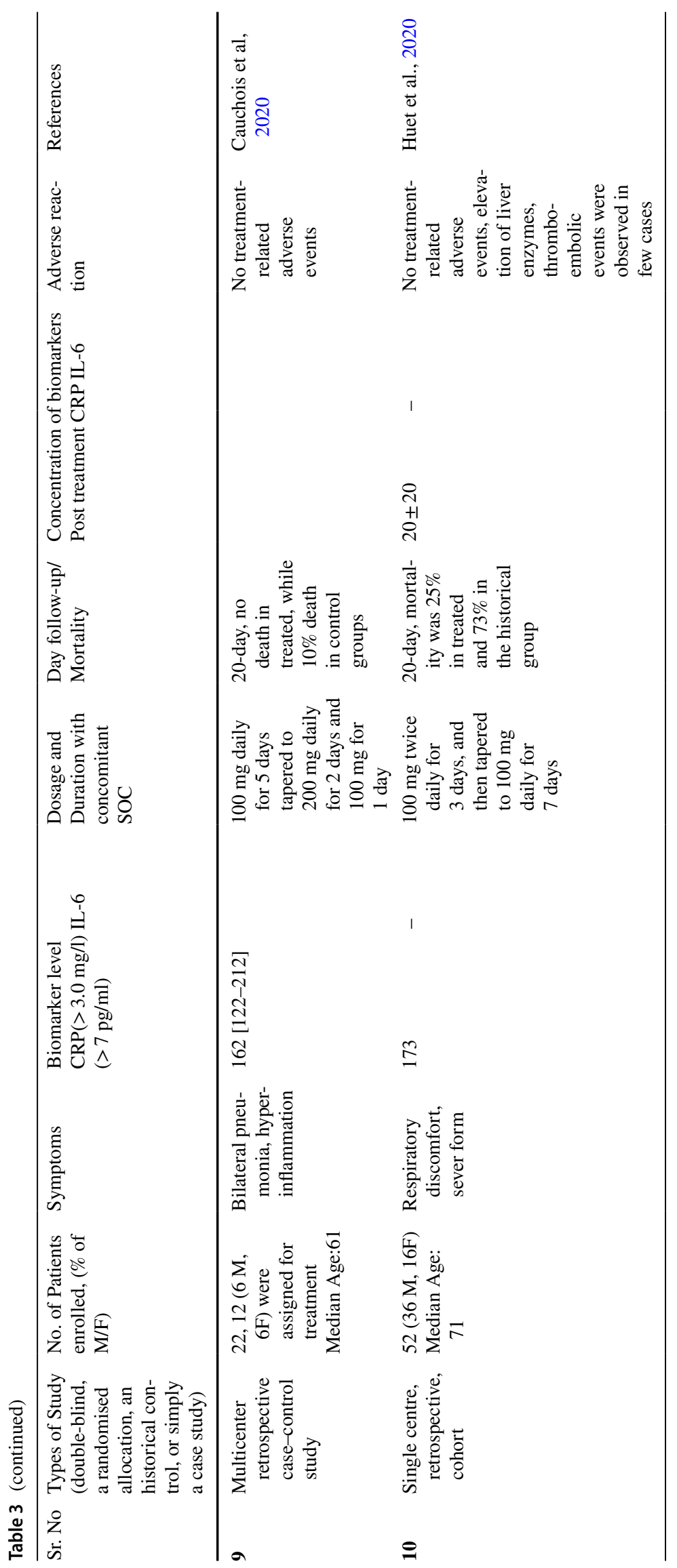




\section{Baricitinib}

Baricitinib (C16H17N7O2S), a reversible JAK inhibitor, i.e. Janus-associated-kinase inhibitor (JAK 1/ JAK 2) is approved in more than 65 countries to treat patients suffering from rheumatoid arthritis (moderate to severe) (Jorgensen et al., 2020). This small molecule not only inhibits the release of cytokines but also reduces the chances of viral entry, and thus seems to be an important drug possessing anti-inflammatory activity (Cantini et al., 2020). Using benevolent algorithms of artificial intelligence and due to the dual effective nature of baricitinib against viral entry and release of cytokines, its use can be predicted in COVID19 infection. The anti-viral efficacy using baricitinib was demonstrated in liver spheroids of humans and showed a good safety profile when administered to patients suffering from COVID-19. Administration of baricitinib to patients reduced the mortality rate, their chances of admission to the intensive care unit, and a drop in the count of viral load was observed when detected through nasopharyngeal swabs (Petrone et al., 2021; Stebbing et al., 2020). Various adaptive treatment trials of COVID-19 showed that baricitinib when used in combination with remdesivir claimed better results in terms of reducing the recovery time and speeding up the status of improvement among COVID-19 patients (Table 4). Various in vitro studies and machine learning algorithms suggested that clathrin-mediated endocytosis in case of SARS CoV-2 can be inhibited using baricitinib due to its affinity towards AP2-associated protein AAK1, which is responsible for reducing the SARS-CoV-2 endocytosis (Cantini et al., 2020).

A study conducted by (Cantini et al., 2020) for duration of 14 days on 12 patients ( 2 females and 10 males) suffering from mild-to-moderate corona disease (CoV-19), the patients were given treatment of baricitinib (4 mg per day) along with ritonavir-lopinavir therapy. The treatment was tolerated normally without any adverse event. However, 1 patient was withdrawn from the study on 10th day due to elevation of transaminases (ALT: $298 \mathrm{U} / \mathrm{L}$; AST: $267 \mathrm{U} / \mathrm{L}$ ), which might be due to anti-viral therapy and not that of baricitinib treatment. Despite this, no other opportunistic or bacterial infection, haematologic toxicity or thrombophlebitis were observed. Significant improvement in parameters of respiratory function and all other clinical characteristic were observed in weeks 1 and 2 in comparison with baseline. The major depiction of the study involved the admission of $33 \%$ (i.e. 4 out of 12) of control group to ICU, which was 0 in case of baricitinib-treated group. Also, discharge rate of the patients in week 2 was $58 \%$ (i.e. 7 out of 12) in case of baricitinib-treated group, which was only $8 \%$ (i.e. 1 out of 12) in case of controls.

Another in vitro study was conducted by (Petrone et al., 2021) to evaluate the effect of baricitinib on the whole blood of 39 COVID-positive patients. Usually, low magnitude of cytokines (Th-2), predominance of Th- 1 and high IFN- $\gamma$ response are associated with immune response of COVID-19 patients. The result of the study depicts that there was significant drop in various immune factors such as IFN- $\gamma$; growth factors (FGF, GM-CSF); pro-inflammatory cytokines such as TNF- $\alpha$, IL-6 and IL-1 $\beta$; Th-2 cytokines including IL-4 and 13, IL-10; chemokines (MIP-1 $\beta$, MCP-1 and IP-10) and other antigens upon baricitinib addition. All these factors are produced by innate immunity cells and by $\mathrm{T}$ and $\mathrm{B}$ cells and are considerably increased during the infection of COVID19. The staphylococcal enterotoxin B-induced response was also dropped significantly upon baricitinib addition. Overall, the study concluded that baricitinib addition is responsible for lowering the SARS-CoV-2-specific response, including in patients suffering from mild or moderate coronavirus disease or in patients having a lymphocyte count of $\geq 1 \times 10^{3} / \mu 1$.

Many other trials and studies have been done and are still in queue by various institutions in different countries to evaluate the effect of baricitinib on COVID-19 patients. Majority of the results confirms the safety of baricitinib therapy in number of clinical trials where no hematological or cardiovascular adverse event or infection took place after two weeks treatment (Cantini et al., 2020). This two-week duration is similar to that of duration in ongoing COVID19 studies involving baricitinib therapy which lasts from 7 to 14 days (Jorgensen et al., 2020). Carpio-Orantes et al., in 2021 enrolled 30 patients, and $90 \%$ of them had moderate and $10 \%$ had severe ARDS. Patients receiving $4 \mathrm{mg} /$ day baricitinib for 14 days demonstrated clinical improvement, with improved oxygen saturation and SAFI after 7 and 14 days of therapy. Ninety percent of patients healed, while ten percent died while undergoing therapy (Carpio-Orantes et al., in 2021). In 2021, Kalil et al. conducted a doubleblind, randomised, placebo-controlled study in which they enrolled 1033 hospitalised COVID-19 patients and treated 515 of them with baricitinib in combination with remdesivir. When compared to remdesivir alone and the placebo group, treatment with combination medication resulted in better clinical results. Patients who received combo treatment healed more quickly than the control group ( 7 days vs. 8 days). Patients on mechanical ventilation respond better to combination treatment, recovering in 10 days compared to 18 days for placebo. The use of combination treatment resulted in fewer side effects (Kalil et al., 2021; Goletti and Cantini 2021). Marconi et al., 2021 conducted a randomised, double-blind, parallel-group, placebo-controlled phase 3 trial, and 1525 participants were enrolled from 101 centres across 12 countries in Asia, Europe, North America, and South America. 764 of them received $4 \mathrm{mg}$ /day baricitinib for 14 days with systemic corticosteroids or 761 patients assigned to placebo group who received only systemic corticosteroids. The baricitinib-treated group had a 


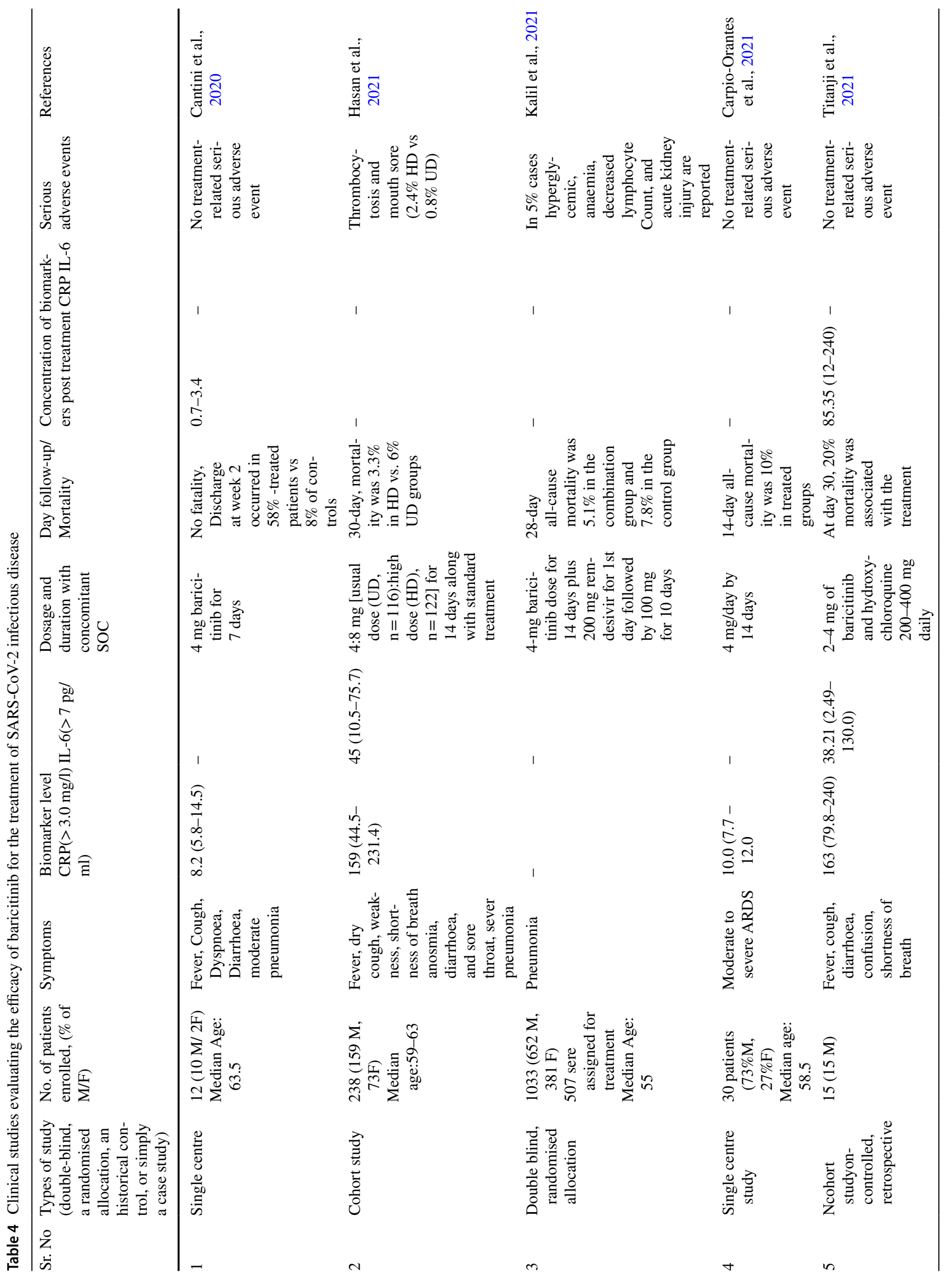




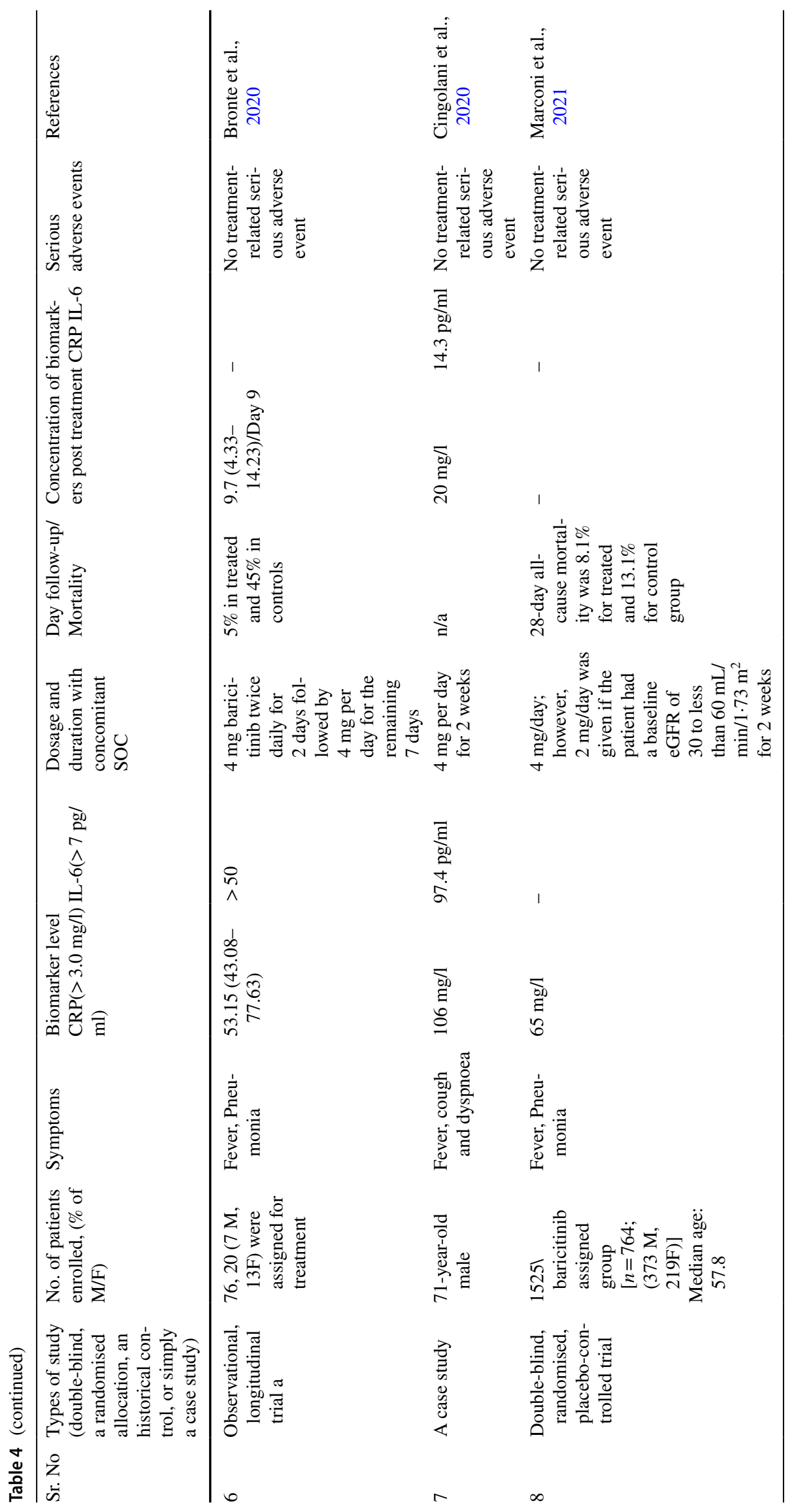


38.2 percent lower death rate on day 28 . On days 28 and 60 , the estimated mortality rate of the baricitinib-treated group was $8 \%(n=62)$ and $10 \%(n=79)$, respectively, compared to placebo, which was $13 \%(\mathrm{n}=100)$ and $15 \%(\mathrm{n}=110)$. In comparison to the placebo, the baricitinib-treated group demonstrated fewer serious adverse reactions like serious infections and venous thromboembolic events (Marconi et al., 2021).

\section{Ruxolitinib}

Early hypercytokinemia causes an increase in IL-6 levels, which activates the Janus kinase-signal transducer and activator of transcription (JAK-STAT) pathway, perpetuating the inflammatory processes. IL- 6 forms a complex with either surface or soluble receptors (mIL-6R or sIL-6R) that activates gp130, which interacts with Janus kinases and regulates levels of cytokines. Blocking signalling events related to or at the level of cytokine production, such as JAK-STAT signalling in macrophages to alleviate IL-1 and IL-6 production, offers a promising therapeutic strategy for overcoming cytokine storm. Ruxolitinib is a JAK $1 / 2$ inhibitor, licensed for use for the treatment of polycythemia vera and myelofibrosis (Ajayi et al., 2018). It has also been reported to be effective in the treatment of secondary hemophagocytic lymphohistiocytosis (Ahmed et al., 2019) by targeting the lethal effects of an aberrant host inflammatory response. Ruxolitinib alleviates the level of pro-inflammatory cytokines (IL-6, TNF- $\alpha$, GM-CSF, MCP-1, and MIP-1 $\alpha$ ) and proliferation of cytotoxic T cells through the activation of regulatory $\mathrm{T}$ cells. Ruxolitinib can be effective against the consequences of the CSS in patients with COVID-19 (Table 5). Cao et al., in 2020 conducted a randomised, multicenter, placebo-controlled, single-blind phase II trial in hospitalised patients with severe COVID-19 to evaluate the efficacy and safety of ruxolitinib. In terms of clinical improvement, however, no significant differences were found, despite the fact that individuals treated with ruxolitinib had a numerically shorter median time to clinical improvement [IQR, 10-19] days vs 15 [IQR, 10-18] days, compared to placebo. In secondary outcomes, administration of ruxolitinib significantly mitigated the exuberant cytokine storm featured in severe COVID-19, alleviated the elevated levels of 48 cytokines, among which the levels of IL-6, NGF, IL-12 (p40), MIF, MIP-1a, MIP- 1b, and VEGF were significantly lower in the ruxolitinib group compared to control group. The finding depicts that ruxolitinib may exert its inhibitory impact on multiple critical cytokines rather than any particular cytokine, and these cytokines could be exploited as surrogate biomarkers in future ruxolitinib trials. Gozzetti et al., 2020 enrolled fourteen patients in their study to check the efficacy of ruxolitinib and administrated it at a dose of $7.5 \mathrm{mg} /$ day for 14 days with a COVID-19
Inflammation Score (CIS) $\geq 10$ out of 16 points. The authors reported that $12 / 14$ patients achieved a significant reduction of CIS by $\geq 25 \%$ on day 7 with a sustained clinical improvement in 11/14 patients. D'Alessio et al., in 2021 conducted a non-randomised clinical study to assess the effect of ruxolitinib in patients with severe COVID-19 pneumonia, without mechanical ventilation. Five mg of ruxolitinib was given orally twice a day for 7 days and then tapered to a single dose per day for up to 10 days. In addition to ruxolitinib, all patients received methylprednisolone $1 \mathrm{mg} / \mathrm{kg}$ intravenously for three days followed by $0.5 \mathrm{mg} / \mathrm{kg}$ for five days and then oral prednisone, which was slowly tapered in the course of 2 weeks. The results depicted that the mortality rate of the treated patients was significantly reduced and there were no significant side effects compared to the control group. Secondary outcomes were decreased inflammatory response, defined as afebrile and 30\% decreased CRP levels at the second clinical observation, i.e. 3-10 days after hospital admission (D'Alessio et al., 2021). In a study by Capochiani et al., 2020, 16 out of 18 enrolled patients exhibited a significant improvement in respiratory responsiveness during the first $48 \mathrm{~h}$. After 7 days of ruxolitinib treatment, $11 / 18$ patients had completely regained respiratory function (pO2 $>98$ percent in spontaneous breathing), 4/18 patients had minimal oxygen requirements $(2-4 \mathrm{~L} / \mathrm{m}), 1 / 18$ patients had stable disease, and 2/18 patients had advancing disease.16/18 patients had perfect respiratory function on day 14 of ruxolitinib therapy. 16/18 patients had perfect respiratory function on day 14 of ruxolitinib therapy. IL-6 levels dropped quickly in responsive patients (16/18). However, the non-responsive patients $(2 / 18)$ showed a substantial rise in IL-6 plasma levels (Capochiani et al., 2020). In patients on ruxolitinib, anaemia is the most prevalent side effect. Longterm ruxolitinib treatment, on the other hand, was associated with a low rate of non-hematological side effects (Kiladjian et al., 2020).

\section{Lenzilumab/mavrilimumab/otilimab (GM-CSF inhibitors)}

GM-CSF is an immunoregulatory cytokine that plays an important role in the onset and progression of inflammatory disorders. GM-CSF levels have recently been found to be elevated in COVID-19 patients (Mehta et al., 2020a, b). Although GM-CSF is considered an appropriate response under some circumstances, in this case, the inflammatory response is observed to be disproportionate. The lung damage caused by COVID-19-induced hyper-inflammation can be improved by blocking the GM-CSF signalling, which can be done by opposition of the GM-CSF receptor or direct binding of circulating GM-CSF (Table 6). COVID19 patients treated with a single dose of mavrilimumab, a 


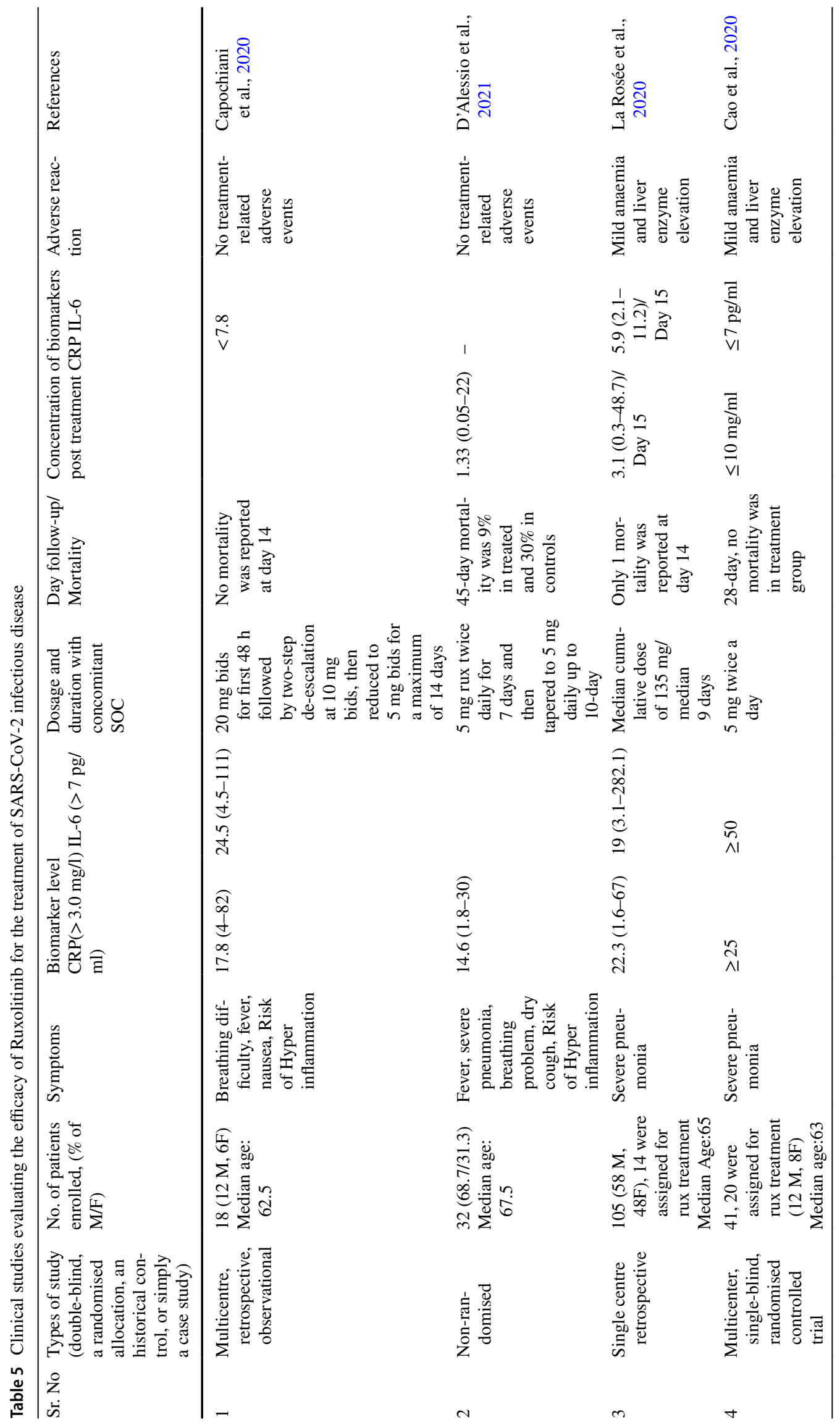




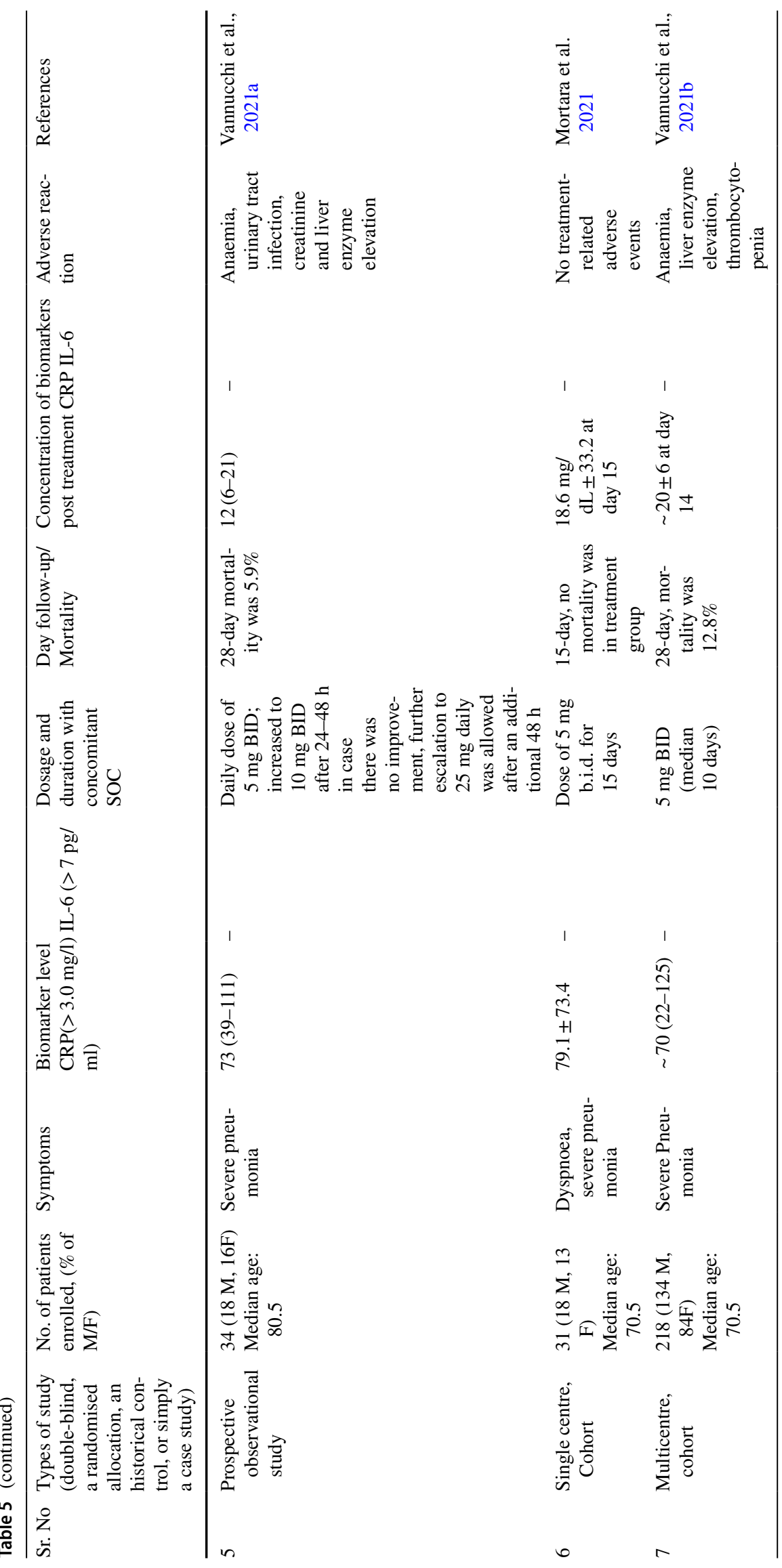




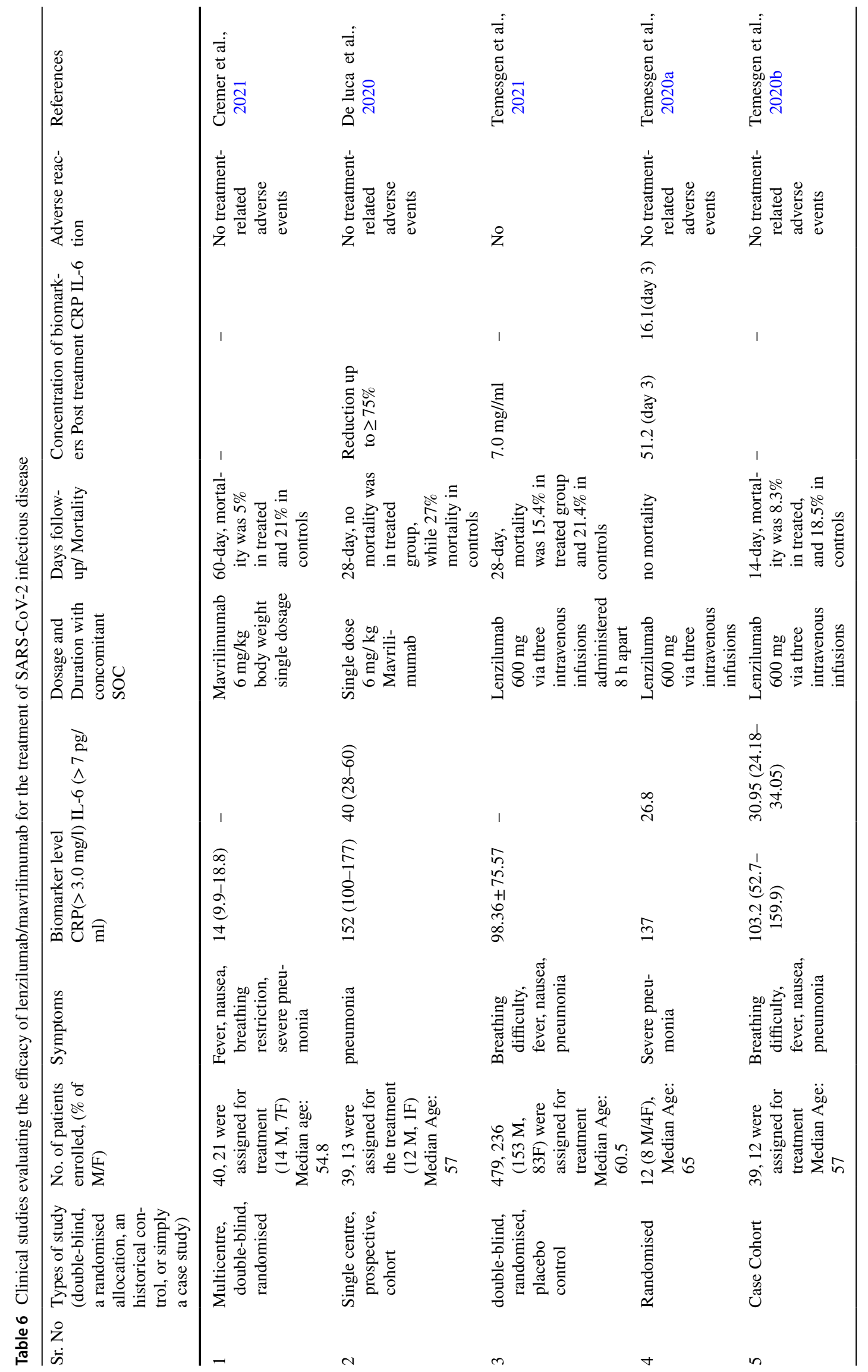


monoclonal antibody which binds to the GM-CSF receptor, showed improvement in oxygenation and resulted in shorter hospitalisations (Bonaventura et al., 2020). Cremer et al., 2021, conducted multicentre, double-blind, randomised trial on 40 hospitalised COVID-19 patients with pneumonia, hypoxaemia and a C-reactive protein $>5 \mathrm{mg} / \mathrm{dL}$. The primary efficacy outcome at day 14 for checking the patients free from mechanical ventilation was found to be $57 \%$ with mavrilimumab as compared to $47 \%$ with placebo; whereas, secondary outcome at day 28 to check the survival ratio was that $95 \%$ of the patients in mavrilimumab group were alive compared to $79 \%$ in untreated. However, the observation was not statistically significant, but this finding hypothesises the need for larger clinical trials to check their efficacy (Cremer et al., 2021).

Lenzilumab is a novel Humaneered ${ }^{\circledR}$ anti-human GMCSF monoclonal antibody that binds directly to the GMCSF and blocks further signalling through its receptor. It also showed strong binding affinity $(25 \mathrm{pM})$ and a slow offrate for glycosylated human GM-CSF (Padron et al., 2013). Temesgen et al., in 2020a, conducted the first clinical trial of Lenzilumab in neutralising the GM-CSF in patients with severe COVID-19-associated pneumonia. In their study, lenzilumab treatment resulted in clinical improvement in 11 out of 12 (92\%), with a median time to discharge of 5 days. On day 3, mean CRP and IL-6 levels improved significantly (137.3 mg/l vs $51.2 \mathrm{mg} / \mathrm{l}, \mathrm{p}=0.040 ; 26.8 \mathrm{pg} / \mathrm{ml}$ vs $16.1 \mathrm{pg} /$ $\mathrm{ml}, p=0.035$, respectively). After two days of lenzilumab therapy, cytokine analysis revealed a decrease in inflammatory myeloid cells. Temesgen et al., 2020b conducted a cohort study to evaluate the efficacy of lenzilumab in the treatment of patients hospitalised with COVID-19 pneumonia. Intravenous treatment with three doses of $600 \mathrm{mg}$ of lenzilumab in 12 patients versus 27 patients comprising the matched control cohort (untreated), led to a significantly shorter time for clinical improvement in lenzilumab-treated patients, with a median of 5 days versus 11 days $(P=0.006)$. Compared to the untreated, the proportion of patients with acute respiratory distress syndrome (oxygen saturation/ fraction of inspired oxygen $<315 \mathrm{~mm} \mathrm{Hg}$ ) was considerably reduced over time when given lenzilumab $(\mathrm{P}<0.001)$. Inflammatory markers (C-reactive protein and interleukin 6) and disease severity markers (absolute lymphocyte count) improved significantly in lenzilumab-treated individuals compared to untreated patients. No treatment-emergent adverse events were associated with lenzilumab. Recently, Temesgen et al., 2021, conducted phase- 3 randomised, double-blind, placebo-controlled study in 520 hospitalised severe COVID-19 patients across 29 sites in the United States and Brazil, and investigated the efficacy and safety of lenzilumab in improving the likelihood of ventilator-free survival without ventilation (SWOV). The likelihood of SWOV through day 28 was reduced by $54 \%$ in COVID-19 hospitalised patients with early treatment with lenzilumab. Although the patients were hypoxic, they did not require mechanical ventilation. The severity of COVID-19 disease is linked to a high level of CRP. In this trial, $77 \%$ of subjects with an evaluable CRP, had a baseline value $<150 \mathrm{mg} / \mathrm{l}$ and $74 \%$ had a baseline CRP value $<150 \mathrm{mg} / \mathrm{l}$ and age $<85$. This study revealed that a CRP level of less than $150 \mathrm{mg} / \mathrm{l}$ was related with obtaining SWOV and distinguished developing hyper-inflammation from full-fledged CSS during the course of treatment. This study also demonstrated that early intervention with lenzilumab led to neutralisation of GMCSF, which is a key factor responsible for initiation of CS in hypoxic patients. This also improved the probability of survival without the usage of mechanical ventilation and provided the greatest benefit over the usage of steroids and/ or remdesivir.

\section{Heparin}

Heparin is a member of a family of polyanionic polysaccharides called glycosaminoglycans (Young, 2008). It is still one of the most commonly prescribed anticoagulants in clinical practice, for the prevention of thrombosis. Heparin has been shown to have various functions in inhibiting SARS-CoV-2 in the treatment of COVID-19 (Hippensteel et al., 2020). It is used as an anticoagulant in treating coagulopathy associated with severe SARS-CoV-2 infection. Tang et al., 2020 were the first to conduct a retrospective, cohort study, including 449 severe COVID-19 patients, 99 of whom had taken low-dose preventive doses of heparin for 7 days or longer. Those who received prophylactic heparin with sepsis-induced coagulopathy (SIC) score $\geq 4$ had $\sim 24.0$ percent lowered mortality than non-users patients ( 40.0 percent vs 64.2 percent, $P=0.029$ ) (Tang et al., 2020).

In 2020, Paranjpe et al., enrolled 2773 hospitalised patients with COVID-19 to evaluate the efficacy of anticoagulant therapy. In-hospital mortality was found to be $29.1 \%$ in patients receiving therapy and on mechanical ventilation support, with a median survival of 21 days, compared to $62.7 \%$ in non-users with a median survival of 9 days (Paranjpe et al 2020). Furthermore, heparin also displayed anti-viral characteristics, a study by Lang et al. 2011 demonstrated that heparinase or exogenous heparin blocked spike protein from attaching to hostile cells and prevented pseudovirus SARS infection. In 2020, using a surface plasmon resonance direct binding assay, Kim et al. demonstrated that the SARS-CoV-2 spike protein formed a highly strong (and nearly irreversible) bond with heparin sulphate, and has shown a greater affinity than either SRS-CoV or MERS-CoV spike protein (Kim et al., 2020). Despite this, few studies showed that the blocking of proinflammatory signalling pathways mediated by MAPK, NF-kB, and STAT-3 was also linked to heparin's protective 
response in sepsis (Iba and Levy, 2017; Li et al., 2020). Heparin has been demonstrated to be easily coupled and absorbed into the cytosolic compartment, where it binds to the positively charged nuclear localisation sequence and prevents NF-kB from translocating to the nucleus (Letourneur et al., 1995; Akimoto et al., 1996; Dudas et al., 2000). The production of pro-inflammatory cytokines, chemokines, and adhesion molecules can be regulated by reducing inflammatory gene activation by blocking of NF-kB. Lower mortality was observed in COVID-19 patients who were treated with heparin, even after taking various parameters like age, gender, oxygen saturation $<90 \%$ and temperature $>37{ }^{\circ} \mathrm{C}$ (Ayerbe et al., 2020). Recently, a study in the US of COVID19-hospitalised patients $(n=786)$ showed that patients who received anticoagulants had a reduced risk of mortality. Studies showed that early treatment with prophylactic anticoagulation resulted in reduced 30-day mortality, compared to no anticoagulation among hospitalised COVID-19 patients (Paranjpe et al., 2020). Amongst the 4297 COVID19 patients admitted, 3627 (84.4\%) who received prophylactic anticoagulation within $24 \mathrm{~h}$ of admission had a $27 \%$ reduced risk for 30-day mortality as compared to patients with no prophylactic administration (Rentsch et al., 2021). The treatments had no increased risk of serious bleeding events. Many more studies suggested that the inhaled unfractionated heparin (UFH) may provide therapeutic advantage over the course of the disease. UHF may prevent infection in upper respiratory tract, given by inhalations into the upper airways, a significant site of entrance for the virus (Haren et al., 2020; Braz-de-Melo et al., 2021).

\section{Antifibrotics (tyrosine kinase inhibitors)}

Nintedanib has been demonstrated to reduce IL-1 concentrations in bronchoalveolar lavage, and pirfenidone has been proven to diminish serum and lung IL-6 concentrations in murine models of pulmonary fibrosis, adding to the biological basis for Nintedanib and pirfenidone's usage in COVID-19. Umemura et al. (2021) conducted an interventional study for evaluation of the safety and efficacy of nintedanib for pulmonary fibrosis in COVID-19 patients with severe pneumonia. There was no significant difference in 28-day mortality in 30 patients that received nintedanib therapy in comparison to 30 control patients not receiving it ( $23.3 \%$ vs $20 \%, \mathrm{P}=0.834$ ). However, the nintedanib group had considerably shorter periods of mechanical ventilation. It was hypothesised that the usage of nintedanib may offer potential benefits in minimising the COVID-19 induced lung injury (Umemura et al., 2021). Based on this observation, Nintedanib was referred for clinical trials to check its efficacy in the treatment of SARS-Cov-2 induced pulmonary fibrosis (NINTECOR) [ClinicalTrials.gov Identifier: NCT04541680]. A case report conducted by Ogata et al., in
2021, on a 78-year-old Japanese woman with no smoking history who suffered from a near-fatal COVID-19, required four-week invasive mechanical ventilation, with subsequent radiological features of pulmonary fibrosis. In parallel with systemic steroids, the patient was also given nintedanib therapy, which led to the patient being able to walk using a walking aid utilising oxygen at $4 \mathrm{~L} / \mathrm{min}$ (Ogata et al., 2021). The current case suggests that nintedanib could be used to treat post COVID-19 fibrosis in a unique way. However, only one patient was examined in this study and more investigations are, thus, necessary.

Pirfenidone, also known as 5-methyl-1-phenyl-2-[1H]pyridone, is a new anti-fibrotic agent with little side effects. Pirfenidone is licenced for the treatment of patients with mild-to-moderate Idiopathic Pulmonary Fibrosis (IPF). Pirfenidone has been shown to suppress apoptosis, downregulate ACE receptor expression, reduce inflammation through a variety of pathways, and alleviate oxidative stress and, thus, protect pneumocytes and other cells from COVID-19 invasion and cytokine storm concurrently. Based on known action mechanism and pathophysiology of pirfenidone for COVID-19 (Seifirad, 2020; Singh et al., 2021), the treatment with pirfenidone for severe COVID-19-related severe ARDS is referred for the clinical trials [Clinical trials NCT04653831].

\section{Conclusion}

Numerous initiatives have been undertaken to combat the SARS-CoV-2 epidemic. Many medicines and vaccines have received emergency approval from the WHO and FDA and are being used to treat the symptoms of this disease. Despite this, outbreaks continue to be diagnosed and spread in a number of countries. The emergence of SARS-CoV-2 variants raises concerns about the efficacy of authorised medicines and vaccines, and we still do not know what the SARS$\mathrm{CoV}-2$ virus and its variants may bring. CSS and ARDS are the most common clinical problems linked to severe instances of COVID-19 illness. The increased cytokine level causes typical organ damage in the more established CSS, although many clinical trials demonstrate that the cytokineblocking yields in clinical benefit and survival. Numerous studies have shown that immunomodulatory treatments can help to reduce the severity of this disease and save lives. However, variability, limited sample sizes, and random recruitment raise concerns about the research that has been undertaken. A number of studies, both supporting and contradictory, have been published. We commended the efforts of all health authorities, supporting personnel, and scientists for identifying potential treatment options for severe instances of COVID-19 illness. Moreover, efforts on a global level are still needed, as demonstrated by the CSS phenotype 
on the severe end of the illness spectrum in COVID-19 patients. Studies should be undertaken with a large sample size with a dysregulated immune response to determine the real effectiveness of immunomodulatory treatments.

Acknowledgements Authors dully acknowledge CSIR, New Delhi and Department of Biotechnology, India for providing financial assistance for COVID-19 testing facility [OLP0043].

Author contributions AK: conceptualisation, acquisition of Data, and wrote manuscript, AK: acquisition of content and wrote manuscript, NVT: Analysis of content and manuscript editing, SK: wrote manuscript, YSP: analysing content, finalising the final version of manuscript, Suresh K; wrote manuscript, SK: devised the project, main conceptual idea and encouraged other authors for opinion.

Funding This work is not supported by any funding agency. Council of Scientific and Industrial Research,India,OLP0043.

Availability of data and materials Not applicable (data transparency).

Code availability Not applicable.

\section{Declarations}

Conflict of interest Authors declare no competing interest.

Ethical approval Not applicable.

Consent to participate Not applicable.

Consent for publication We authorise the publisher to publish this manuscript.

\section{References}

Ahmed A, Merrill SA, Alsawah F et al (2019) Ruxolitinib in adult patients with secondary haemophagocytic lymphohistiocytosis: an open-label, single-centre, pilot trial. Lancet Haematol 6:e630 e637. https://doi.org/10.1016/s2352-3026(19)30156-5

Ajayi S, Becker H, Reinhardt H, et al (2018) Ruxolitinib. Small Mol. Hematol. 119-132.

Akimoto H, Ito H, Tanaka M et al (1996) Heparin and heparan sulfate block angiotensin iiinduced hypertrophy in cultured neonatal rat cardiomyocytes. Circulation 93:810-816. https://doi.org/10. 1161/01.cir.93.4.810

Alattar R, Ibrahim TBH, Shaar SH et al (2020) Tocilizumab for the treatment of severe coronavirus disease 2019. J Med Virol 92:2042-2049. https://doi.org/10.1002/jmv.25964

Aomar-Millán IF, Salvatierra J, Torres-Parejo Ú et al (2021) Anakinra after treatment with corticosteroids alone or with tocilizumab in patients with severe COVID-19 pneumonia and moderate hyperinflammation. A retrospective cohort study. Intern Emerg Med 16:843-852. https://doi.org/10.1007/ s11739-020-02600-z

Ayerbe L, Risco C, Ayis S (2020) The association between treatment with heparin and survival in patients with Covid-19. J Thromb Thrombolysis 50:298-301. https://doi.org/10.1007/ s11239-020-02162-z
Bae S-C, Lee YH (2017) Comparative efficacy and tolerability of sarilumab 150 and $200 \mathrm{mg}$ in patients with active rheumatoid arthritis. Z Rheumatol 77:421-428. https://doi.org/10.1007/ s00393-017-0292-6

Balkhair A, Al-Zakwani I, Al Busaidi M et al (2021) (2021) Anakinra in hospitalized patients with severe COVID-19 pneumonia requiring oxygen therapy: results of a prospective, open-label, interventional study. Int J Infect Dis 103:288-296. https://doi. org/10.1016/j.ijid.2020.11.149

Bartlett RH et al (2020) Initial ELSO guidance document: ECMO for COVID-19 patients with severe cardiopulmonary failure. ASAIO J 66:472-474. https://doi.org/10.1097/MAT.0000000000001173

Benucci M, Giannasi G, Cecchini P et al (2020) COVID-19 pneumonia treated with Sarilumab: A clinical series of eight patients. J Med Virol 92:2368-2370. https://doi.org/10.1002/jmv.26062

Bhaskar S, Sinha A, Banach M et al (2020) Cytokine storm in COVID19-immunopathological mechanisms, clinical considerations, and therapeutic approaches: the reprogram consortium position paper. Front Immunol. https://doi.org/10.3389/FIMMU.2020. 01648

Bhatraju PK, Ghassemieh BJ, Nichols M et al (2020) COVID-19 in critically ill patients in the Seattle region - case series. N Engl $\mathrm{J}$ Med 382:2012-2022

Blanco-Melo D, Nilsson-Payant BE, Liu W-C et al (2020) Imbalanced host response to SARS-CoV-2 drives development of COVID19. Cell 181:1036-1045.e9. https://doi.org/10.1016/j.cell.2020. 04.026

Bonaventura A, Vecchié A, Wang TS et al (2020) Targeting GM-CSF in COVID-19 pneumonia: rationale and strategies. Front Immunol. https://doi.org/10.3389/fimmu.2020.01625

Bozzi G, Mangioni D, Minoia F et al (2021) Anakinra combined with methylprednisolone in patients with severe COVID-19 pneumonia and hyperinflammation: An observational cohort study. J Allergy Clin Immunol 147(2):561-566.e4. https://doi.org/10. 1016/j.jaci.2020.11.006

Braz-de-Melo HA, Faria SS, Pasquarelli-do-Nascimento G et al (2021) The use of the anticoagulant heparin and corticosteroid dexamethasone as prominent treatments for COVID-19. Front Med. https://doi.org/10.3389/FMED.2021.615333

Bronte V, Ugel S, Tinazzi E et al (2020) (2020) Baricitinib restrains the immune dysregulation in patients with severe COVID-19. J Clin Invest 130(12):6409-6416. https://doi.org/10.1172/JCI141772

Cantini F, Niccoli L, Matarrese D et al (2020) Baricitinib therapy in COVID-19: A pilot study on safety and clinical impact. J Infect 81:318-356. https://doi.org/10.1016/j.jinf.2020.04.017

Cao Y, Wei J, Zou L et al (2020) (2020) Ruxolitinib in treatment of severe coronavirus disease 2019 (COVID-19): a multicenter, single-blind, randomized controlled trial. J Allergy Clin Immunol 146(1):137-146.e3. https://doi.org/10.1016/j.jaci.2020.05.019

Capochiani E, Frediani B, Iervasi G et al (2020) Ruxolitinib rapidly reduces acute respiratory distress Syndrome in COVID-19 disease. Analysis of data collection from RESPIRE protocol. Front Med 7:466. https://doi.org/10.3389/fmed.2020.00466

Capra R, De Rossi N, Mattioli F et al (2020) Impact of low dose tocilizumab on mortality rate in patients with COVID-19 related pneumonia. Eur J Intern Med 76:31-35. https://doi.org/10. 1016/j.ejim.2020.05.009

Carpio-Orantes LD, Méndez SG, López-Guzmán C et al (2021) (2021) Baricitinib in patients with severe pneumonia due to COVID19 in Veracruz, Mexico. J Anesth Crit Care Open Access 13(1):17-20

Cate H ten (2021) Surviving Covid-19 with Heparin? 385:845-846. https://doi.org/10.1056/NEJME2111151

Cauchois R, Koubi M, Delarbre D et al (2020) Early IL-1 receptor blockade in severe inflammatory respiratory failure complicating 
COVID-19. Proc Natl Acad Sci U S A 117(32):18951-18953. https://doi.org/10.1073/pnas.2009017117

Cavalli G, De Luca G, Campochiaro C et al (2020) Interleukin-1 blockade with high-dose anakinra in patients with COVID-19, acute respiratory distress syndrome, and hyperinflammation: a retrospective cohort study. Lancet Rheumatol 2(6):e325-e331. https:// doi.org/10.1016/S2665-9913(20)30127-2

Chen H, Wang F, Zhang P et al (2019) Management of cytokine release syndrome related to CAR-T cell therapy. Front Med 13:610-617. https://doi.org/10.1007/s11684-019-0714-8

Chen G, Wu D, Guo W et al (2020) Clinical and immunological features of severe and moderate coronavirus disease 2019. J Clin Invest 130:2620-2629. https://doi.org/10.1172/jci137244

Cingolani A, Tummolo AM, Montemurro G et al (2020) Baricitinib as rescue therapy in a patient with COVID-19 with no complete response to sarilumab. Infection 48:767-771. https://doi.org/10. 1007/s15010-020-01476-7

Clyne B, Olshaker JS (1999) The C-reactive protein. J Emerg Med 17(6):1019-25. pmid:10595891

Coomes EA, Haghbayan H (2020) Interleukin-6 in Covid-19: a systematic review and meta-analysis. Rev Med Virol 30:1-9. https:// doi.org/10.1002/rmv.2141

Cooper AM, Khader SA (2007) IL-12p40: an inherently agonistic cytokine. Trends Immunol 28:33-38. https://doi.org/10.1016/j. it.2006.11.002

CORIMUNO-19 Collaborative group 2021 Effect of anakinra versus usual care in adults in hospital with COVID-19 and mild-tomoderate pneumonia (CORIMUNO-ANA-1): a randomised controlled trial Lancet Respir Med 9295304 https://doi.org/10. 1016/S2213-2600(20)30556-7

Costela-Ruiz VJ, Illescas-Montes R, Puerta-Puerta JM et al (2020) SARS-CoV-2 infection: The role of cytokines in COVID-19 disease. Cytokine Growth Factor Rev 54:62. https://doi.org/10. 1016/J.CYTOGFR.2020.06.001

Crayne CB, Albeituni S, Nichols KE, Cron RQ (2019) The Immunology of Macrophage Activation Syndrome. Front Immunol. https://doi.org/10.3389/fimmu.2019.00119

Cremer PC, Abbate A, Hudock K et al (2021) Mavrilimumab in patients with severe COVID-19 pneumonia and systemic hyperinflammation (MASH-COVID): an investigator initiated, multicentre, double-blind, randomised, placebo-controlled trial. Lancet Rheumatol 3:e410-e418. https://doi.org/10.1016/s26659913(21)00070-9

D’Alessio A, Del Poggio P, Bracchi F et al (2021) Low-dose ruxolitinib plus steroid in severe SARS-CoV-2 pneumonia. Leukemia 35:635-638

de la Calle C, López-Medrano F, Pablos JL et al (2021) (2021) Effectiveness of anakinra for tocilizumab-refractory severe COVID19: A single-centre retrospective comparative study. Int J Infect Dis 105:319-325. https://doi.org/10.1016/j.ijid.2021.02.041

De Luca G, Cavalli G, Campochiaro C et al (2020) (2020) GM-CSF blockade with mavrilimumab in severe COVID-19 pneumonia and systemic hyperinflammation: a single-centre, prospective cohort study. Lancet Rheumatol 2(8):e465-e473. https://doi. org/10.1016/S2665-9913(20)30170-3

de Wit E, van Doremalen N, Falzarano D, Munster VJ (2016) SARS and MERS: recent insights into emerging coronaviruses. Nat Rev Microbiol 14:523-534. https://doi.org/10.1038/nrmicro.2016.81

Della-Torre E, Lanzillotta M, Campochiaro C, Cavalli G, De Luca G et al (2021) Respiratory Impairment Predicts Response to IL-1 and IL-6 Blockade in COVID-19 Patients With Severe Pneumonia and Hyper-Inflammation. Front Immunol 12:675678. https://doi.org/10.3389/fimmu.2021.675678

Della-Torre E, Campochiaro C, Cavalli G SARI-RAF Study Group, et al (2020) Interleukin-6 blockade with sarilumab in severe COVID-19 pneumonia with systemic hyperinflammation: an open-label cohort study. Annals of the Rheumatic Diseases, 79:1277-1285

Dudas J, Ramadori G, Knittel T et al (2000) Effect of heparin and liver heparan sulphate on interaction of HepG2-derived transcription factors and their cis-acting elements: altered potential of hepatocellular carcinoma heparan sulphate. Biochem J 350:245-251. https://doi.org/10.1042/bj3500245

England JT, Abdulla A, Biggs CM et al (2021) Weathering the COVID19 storm: Lessons from hematologic cytokine syndromes. Blood Rev 45:100707. https://doi.org/10.1016/j.blre.2020.100707

Fara A, Mitrev Z, Rosalia RA, Assas BM (2020) Cytokine storm and COVID-19: a chronicle of pro-inflammatory cytokines. Open Biol. https://doi.org/10.1098/RSOB.200160

Filocamo G, Mangioni D, Tagliabue P et al (2020) Use of anakinra in severe COVID-19: a case report. Int J Infect Dis 96:607-609. https://doi.org/10.1016/j.ijid.2020.05.026

Fodor A, Tiperciuc B, Login C et al (2021) Endothelial Dysfunction, Inflammation, and Oxidative Stress in COVID-19-Mechanisms and Therapeutic Targets. Oxid Med Cell Longev 2021:1-15. https://doi.org/10.1155/2021/8671713

Franzetti M, Forastieri A, Borsa N et al (2021) IL-1 receptor antagonist anakinra in the treatment of COVID-19 acute respiratory distress syndrome: a retrospective. Observational Study J Immunol 206(7):1569-1575. https://doi.org/10.4049/jimmunol.2001126

Giamarellos-Bourboulis EJ, Netea MG, Rovina N et al (2020) Complex immune dysregulation in COVID-19 patients with severe respiratory failure. Cell Host Microbe 27:992-1000.e3. https://doi.org/ 10.1016/j.chom.2020.04.009

Goletti D, Cantini F (2021) Baricitinib therapy in Covid-19 pneumonia - an unmet need fulfilled. N Engl J Med 384(9):867-869. https:// doi.org/10.1056/NEJMe2034982

Gremese E, Cingolani A, Bosello SL et al (2020) Sarilumab use in severe SARS-CoV-2 pneumonia. EClinicalMedicine 27:100553. https://doi.org/10.1016/j.eclinm.2020.100553

Guillén L, Padilla S, Fernández M et al (2020) Preemptive interleukin-6 blockade in patients with COVID-19. Sci Rep 10:16826. https://doi.org/10.1038/s41598-020-74001-3

Gupta S, Wang W, Hayek SS et al (2021) Association between early treatment with tocilizumab and mortality among critically ill Patients with COVID-19. JAMA Intern Med 181(1):41-51. https://doi.org/10.1001/jamainternmed.2020.6252

Hamilton JA (2019) GM-CSF in inflammation. J Exp Med. https://doi. org/10.1084/jem.20190945

Hasan MJ, Rabbani R, Anam AM et al (2021) Impact of high dose of baricitinib in severe COVID-19 pneumonia: a prospective cohort study in Bangladesh. BMC Infect Dis 21:427. https://doi.org/10. 1186/s12879-021-06119-2

Hermine O, Mariette X, Tharaux PL et al (2021) Effect of tocilizumab vs usual care in adults hospitalized with COVID-19 and moderate or severe pneumonia: a randomized clinical trial. JAMA Intern Med 181(1):32-40. https://doi.org/10.1001/jamaintern med.2020.6820

Herold T, Jurinovic V, Arnreich C et al (2020) Elevated levels of IL-6 and CRP predict the need for mechanical ventilation in COVID19. J Allergy Clin Immunol 146:128-136.e4. https://doi.org/10. 1016/j.jaci.2020.05.008

Hippensteel JA, LaRiviere WB, Colbert JF, et al (2020) Heparin as a therapy for COVID-19: current evidence and future possibilities. 319:L211-L217. https://doi.org/10.1152/AJPLUNG.00199.2020

Hoiland RL, Stukas S, Cooper J et al (2020) Amelioration of COVID19-related cytokine storm syndrome: parallels to chimeric antigen receptor-T cell cytokine release syndrome. Br J Haematol. https://doi.org/10.1111/bjh.16961

Huet T, Beaussier H, Voisin O et al (2020) Anakinra for severe forms of COVID-19: a cohort study. Lancet Rheumatol 2(7):e393-e400. https://doi.org/10.1016/S2665-9913(20)30164-8 
Iba T, Levy JH (2017) Inflammation and thrombosis: roles of neutrophils, platelets and endothelial cells and their interactions in thrombus formation during sepsis. J Thromb Haemost 16:231241. https://doi.org/10.1111/jth.13911

Gordon AC, Mouncey PR, Al-Beidh F, Rowan KM, Nichol AD, R-C Investigators et al (2021) Interleukin-6 receptor antagonists in critically ill patients with COVID-19. N Engl J Med 384(16):1491-1502

Jorgensen SCJ, Tse CLY, Burry L, Dresser LD (2020) Baricitinib: A Review of Pharmacology, Safety, and Emerging Clinical Experience in COVID-19. Pharmacother J Hum Pharmacol Drug Ther 40:843-856. https://doi.org/10.1002/phar.2438

Kalil AC, Patterson TF, Mehta AK et al (2021) Baricitinib plus Remdesivir for Hospitalized Adults with Covid-19. N Engl J Med 384(9):795-807. https://doi.org/10.1056/NEJMoa2031994

Kewana T, Covuta F, AlJaghbeerb MJ et al (2020) Tocilizumab for treatment of patients with severe COVID19: A retrospective cohort study. Clinical Medicine 24:100418

Khadke S, Ahmed N, Ahmed N et al (2020) Harnessing the immune system to overcome cytokine storm and reduce viral load in COVID-19: a review of the phases of illness and therapeutic agents. Virol J 171(17):1-18. https://doi.org/10.1186/ S12985-020-01415-W

Khiali S, Rezagholizadeh A, Entezari-Maleki T (2020) A comprehensive review on sarilumab in COVID-19. Expert Opin Biol Ther 21:615-626. https://doi.org/10.1080/14712598.2021.1847269

Kiladjian J-J, Zachee P, Hino M et al (2020) Long-term efficacy and safety of ruxolitinib versus best available therapy in polycythaemia vera (RESPONSE): 5-year follow up of a phase 3 study. Lancet Haematol 7:e226-e237. https://doi.org/10.1016/s23523026(19)30207-8

Kim SY, Jin W, Sood K, et al (2020) Glycosaminoglycan binding motif at $\mathrm{S} 1 / \mathrm{S} 2$ proteolytic cleavage site on spike glycoprotein may facilitate novel coronavirus (SARS-CoV-2) host cell entry. bioRxiv. doi: https://doi.org/10.1101/2020.04.14.041459

Ko J-H, Park GE, Lee JY, et al (2016) Predictive factors for pneumonia development and progression to respiratory failure in MERS-CoV infected patients. J Infect 73(5):468-75. pmid:27519621

Kotch C, Barrett D, Teachey DT (2019) Tocilizumab for the treatment of chimeric antigen receptor T cell-induced cytokine release syndrome. Expert Rev Clin Immunol 15:813-822. https://doi.org/ 10.1080/1744666x.2019.1629904

Kumar A, Sharma A, Tirpude NV et al (2021) Combating the progression of novel coronavirus SARS-CoV-2 infectious Disease: Current state and future prospects in molecular diagnostic and drug discovery. Curr Mol Med. https://doi.org/10.2174/15665 24021666210803154250

Kyriazopoulou E, Panagopoulos P, Metallidis S et al (2021) An open label trial of anakinra to prevent respiratory failure in COVID-19. Elife 10:e66125. https://doi.org/10.7554/eLife.66125

La Rosée F, Bremer HC, Gehrke I et al (2020) The Janus kinase 1/2 inhibitor ruxolitinib in COVID-19 with severe systemic hyperinflammation. Leukemia 34:1805-1815. https://doi.org/10.1038/ s41375-020-0891-0

Laguna-Goya R, Utrero-Rico A, Talayero P et al (2020) IL-6-based mortality risk model for hospitalized patients with COVID-19. J Allergy Clin Immunol 146:799-807.e9. https://doi.org/10.1016/j. jaci.2020.07.009

Laing AG, Lorenc A, del Molino del Barrio I et al (2020) A dynamic COVID-19 immune signature includes associations with poor prognosis. Nat Med 26:1623-1635. https://doi.org/10.1038/ s41591-020-1038-6

Lang J, Yang N, Deng J et al (2011) Inhibition of SARS Pseudovirus Cell Entry by Lactoferrin Binding to Heparan Sulfate
Proteoglycans. PLoS ONE 6:e23710. https://doi.org/10.1371/ Journal.Pone.0023710

Langer-Gould A, Smith JB, Gonzales EG et al (2020) Early identification of COVID-19 cytokine storm and treatment with anakinra or tocilizumab. Int J Infect Dis 99:291-297. https://doi.org/10. 1016/j.ijid.2020.07.081

Leisman DE, Deutschman CS, Legrand M (2020) Facing COVID-19 in the ICU: vascular dysfunction, thrombosis, and dysregulated inflammation. Intensive Care Med 46:1105-1108. https://doi.org/ 10.1007/s00134-020-06059-6

León López R, Fernández SC, Limia Pérez L et al (2020) Efficacy and safety of early treatment with sarilumab in hospitalised adults with COVID-19 presenting cytokine release syndrome (SARICOR STUDY): protocol of a phase II, open-label, randomised, multicentre, controlled clinical trial. BMJ Open 10:e039951. https://doi.org/10.1136/bmjopen-2020-039951

Lescure FX, Honda H, Fowler RA et al (2021) (2021) Sarilumab in patients admitted to hospital with severe or critical COVID-19: a randomised, double-blind, placebo-controlled, phase 3 trial. Lancet Respir Med 9(5):522-532. https://doi.org/10.1016/S22132600(21)00099-0

Letourneur D, Caleb BL, Castellot JJ (1995) Heparin binding, internalization, and metabolism in vascular smooth muscle cells: I. Upregulation of heparin binding correlates with antiproliferative activity. J Cell Physiol 165:676-686. https://doi.org/10.1002/jcp. 1041650327

Li X, Li L, Shi Y et al (2020) Different signaling pathways involved in the anti-inflammatory effects of unfractionated heparin on lipopolysaccharide-stimulated human endothelial cells. J Inflamm (lond) 17(5):10. https://doi.org/10.1186/ s12950-020-0238-7

Liu T., Zhang J., Yang Y., Ma H., et al., (2020) The potential role of IL-6 in monitoring severe case of coronavirus disease 2019. medRxiv. 2020;2020 03.01.20029769

Luo P, Liu Y, Qiu L, Liu X, Liu D, Li J (2020) Tocilizumab treatment in COVID-19: a single center experience. J Med Virol 92(7):814-818. https://doi.org/10.1002/jmv.25801

Marconi VC, Ramanan AV, de Bono S et al (2021) Efficacy and safety of baricitinib for the treatment of hospitalised adults with COVID-19 (COV-BARRIER): a randomised, double-blind, parallel-group, placebo-controlled phase 3 trial. Lancet Respir Med 9(10):

Matthay MA et al (2019) Acute respiratory distress syndrome. Nat Rev Dis Primers 371(5):372

Mazzoni A, Salvati L, Maggi L et al (2020) Impaired immune cell cytotoxicity in severe COVID-19 is IL-6 dependent. J Clin Invest 130:4694-4703. https://doi.org/10.1172/jci138554

Mehta P, Porter JC, Manson JJ et al (2020a) Therapeutic blockade of granulocyte macrophage colony-stimulating factor in COVID19-associated hyperinflammation: challenges and opportunities. Lancet Respir Med 8:822-830. https://doi.org/10.1016/s22132600(20)30267-8

Mehta P, McAuley DF, Brown M et al (2020b) COVID-19: consider cytokine storm syndromes and immunosuppression. Lancet 395(10229):1033-1034. https://doi.org/10.1016/S0140-6736(20) 30628-0

Menten P, Wuyts A, Van Damme J (2002) Macrophage inflammatory protein-1. Cytokine Growth Factor Rev 13:455-481. https://doi. org/10.1016/s1359-6101(02)00045-x

Montesarchio V, Parrela R, Iommelli C et al (2020) Outcomes and biomarker analyses among patients with COVID-19 treated with interleukin 6 (IL-6) receptor antagonist sarilumab at a single institution in Italy [published correction appears in J Immunother Cancer. J Immunother Cancer 8(2):e001089. https://doi.org/10. 1136/jitc-2020-001089 
Mortara A, Mazzetti S, Margonato D et al., (2021) Compassionate use of ruxolitinib in patients with SARS-Cov-2 infection not on mechanical ventilation: Short-term effects on inflammation and ventilation Clin Transl Sci. 2021;14:1062-1068

Navarro-Millán I, Sattui SE, Lakhanpal A et al (2020) Use of anakinra to prevent mechanical ventilation in severe COVID-19: a case series. Arthritis Rheumatol 72:1990-1997. https://doi.org/10. 1002/art.41422

Ogata H, Nakagawa T, Sakoda S et al (2021) Nintedanib treatment for pulmonary fibrosis after coronavirus disease 2019. Respirol Case Reports. https://doi.org/10.1002/rcr2.744

Padron E, Painter JS, Kunigal S et al (2013) GM-CSF-dependent pSTAT5 sensitivity is a feature with therapeutic potential in chronic myelomonocytic leukemia. Blood 121:5068-5077. https://doi.org/10.1182/blood-2012-10-460170

Paranjpe I, Fuster V, Lala A et al (2020) Association of treatment dose anticoagulation with in-hospital survival among hospitalized patients With COVID-19. J Am Coll Cardiol 76:122-124. https:// doi.org/10.1016/j.jacc.2020.05.001

Petrone L, Petruccioli E, Vanini V et al (2021) In-vitro evaluation of the immunomodulatory effects of Baricitinib: Implication for COVID-19 therapy. Infect 82(4):58-66. https://doi.org/10.1016/j. cmi.2020.09.051

Pontali E, Volpi S, Signori A et al (2021) Efficacy of early anti-inflammatory treatment with high doses of intravenous anakinra with or without glucocorticoids in patients with severe COVID-19 pneumonia. J Allergy Clin Immunol 147(4):1217-1225. https:// doi.org/10.1016/j.jaci.2021.01.024

Ragab D, Salah Eldin H, Taeimah M et al (2020) The COVID-19 cytokine storm; what we know so far. Front Immunol. https:// doi.org/10.3389/FIMMU.2020.01446

RECOVERY Collaborative Group, Horby P, Lim WS et al (2021) Dexamethasone in hospitalized patients with Covid-19. N Engl J Med 384(8):693-704. https://doi.org/10.1056/NEJMoa2021436

Rentsch CT, Beckman JA, Tomlinson L et al (2021) Early initiation of prophylactic anticoagulation for prevention of coronavirus disease 2019 mortality in patients admitted to hospital in the United States: cohort study. BMJ 372:n311. https://doi.org/10. 1136/bmj.n311

Rohilla S (2020) Designing therapeutic strategies to combat severe acute respiratory syndrome coronavirus-2 disease: COVID -19 . Drug Dev Res 82:12-26. https://doi.org/10.1002/ddr.21720

Salvarani C, Dolci G, Massari M et al (2021) Effect of tocilizumab vs standard care on clinical worsening in patients hospitalized with COVID-19 pneumonia: a randomized clinical trial. JAMA Intern Med 181(1):24-31. https://doi.org/10.1001/jamaintern med.2020.6615

Sancho-López A, Caballero-Bermejo AF, Ruiz-Antorán B et al (2021) Efficacy and safety of sarilumab in patients with COVID19 pneumonia: a randomized, phase III clinical trial (SARTRE Study). Infect Dis Ther 10(4):2735-2748. https://doi.org/10.1007/ s40121-021-00543-2

Schmidt-Arras D, Rose-John S (2016) IL-6 pathway in the liver: from physiopathology to therapy. J Hepatol 64:1403-1415. https://doi. org/10.1016/j.jhep.2016.02.004

Schulz O, Hammerschmidt SI, Moschovakis GL, Förster R (2016) Chemokines and chemokine receptors in lymphoid tissue dynamics. Annu Rev Immunol 34:203-242. https://doi.org/10.1146/ annurev-immunol-041015-055649

Seifirad S (2020) Pirfenidone: a novel hypothetical treatment for COVID-19. Med Hypotheses 144:110005. https://doi. org/10.1016/j.mehy.2020.110005

Sharifpour M, Rangaraju S, Liu M, Alabyad D, Nahab FB, CreelBulos CM et al (2020) C-Reactive protein as a prognostic indicator in hospitalized patients with COVID-19. PLoS ONE 15(11):e0242400. https://doi.org/10.1371/journal.pone.0242400
Singh E, Matada GSP, Abbas N et al (2021) Management of COVID-19-induced cytokine storm by Keap1-Nrf2 system: a review. Inflammopharmacology 1:1. https://doi.org/10.1007/ S10787-021-00860-5

Sinha P, Matthay MA, Calfee CS (2020a) Is a "Cytokine storm" relevant to COVID-19? JAMA Intern Med 180:1152. https://doi. org/10.1001/jamainternmed.2020.3313

Sinha P, Mostaghim A, Bielick CG et al (2020b) Early administration of interleukin-6 inhibitors for patients with severe COVID-19 disease is associated with decreased intubation, reduced mortality, and increased discharge. Int J Infect Dis 99:28-33. https:// doi.org/10.1016/j.ijid.2020.07.023

Stebbing J, Krishnan V, de Bono S et al (2020) Mechanism of baricitinib supports artificial intelligence-predicted testing in COVID19 patients. EMBO Mol Med 12(8):e12697. https://doi.org/10. 15252/emmm.202012697

Stone JH, Frigault MJ, Serling-Boyd NJ et al (2020) Efficacy of tocilizumab in patients hospitalized with Covid-19. N Engl J Med 383(24):2333-2344. https://doi.org/10.1056/NEJMoa2028836

Streeck H, Schulte B, Kümmerer BM et al (2020) Infection fatality rate of SARS-CoV2 in a super-spreading event in Germany. Nat Commun 11(1):5829. https://doi.org/10.1038/s41467-020-19509-y

Stukas S, Hoiland RL, Cooper J et al (2020) The Association of Inflammatory Cytokines in the Pulmonary Pathophysiology of Respiratory Failure in Critically Ill Patients With Coronavirus Disease 2019. Crit Care Explor 2:e0203. https://doi.org/10.1097/CCE. 0000000000000203

Tang N, Bai H, Chen X et al (2020) Anticoagulant treatment is associated with decreased mortality in severe coronavirus disease 2019 patients with coagulopathy. J Thromb Haemost 18:1094-1099. https://doi.org/10.1111/JTH.14817

Temesgen Z, Assi M, Shweta FNU et al (2020a) GM-CSF Neutralization With Lenzilumab in Severe COVID-19 Pneumonia: A Case-Cohort Study. Mayo Clin Proc 95(11):2382-2394. https:// doi.org/10.1016/j.mayocp.2020.08.038

Temesgen Z, Assi M, Vergidis P et al (2020b) First clinical use of lenzilumab to neutralize gm-csf in patients with severe COVID19 Pneumonia. Preprint Medrxiv. https://doi.org/10.1101/2020. 06.08.20125369

Temesgen Z, Burger CD, Baker J, et al. (2021) Lenzilumab Efficacy And Safety In Newly Hospitalized Covid-19 Subjects: Results From The Live-Air Phase 3 Randomized Double-Blind PlaceboControlled Trial. Preprint. medRxiv. 2021;2021.05.01.21256470. doi:https://doi.org/10.1101/2021.05.01.21256470

Thompson RN, Hill EM, Gog JR (2021) SARS-CoV-2 incidence and vaccine escape. Lancet Infect Dis 21:913-914. https://doi.org/ 10.1016/s1473-3099(21)00202-4

Titanji BK, Farley MM, Mehta A et al (2021) Use of baricitinib in patients with moderate to severe coronavirus disease 2019. Clin Infect Dis 72(7):1247-1250. https://doi.org/10.1093/cid/ciaa879

Toniati P, Piva S, Cattalini M et al (2020) Tocilizumab for the treatment of severe COVID-19 pneumonia with hyperinflammatory syndrome and acute respiratory failure: A single center study of 100 patients in Brescia, Italy. Autoimmun Rev 19(7):102568. https://doi.org/10.1016/j.autrev.2020.102568

Umemura Y, Mitsuyama Y, Minami K et al (2021) Efficacy and safety of nintedanib for pulmonary fibrosis in severe pneumonia induced by COVID-19: An interventional study. Int J Infect Dis 108:454-460. https://doi.org/10.1016/j.ijid.2021.05.055

van Haren FMP, Page C, Laffey JG et al (2020) (2020) Nebulised heparin as a treatment for COVID-19: scientific rationale and a call for randomised evidence. Crit Care 241(24):1-11. https://doi.org/ 10.1186/S13054-020-03148-2

van Rhee F, Wong RS, Munshi N et al (2014) Siltuximab for multicentric Castleman's disease: a randomised, double-blind, 
placebo-controlled trial. Lancet Oncol 15:966-974. https://doi. org/10.1016/s1470-2045(14)70319-5

Vannucchi, A.M., Sordi, B., Morettini, A. et al. (2021 a). Compassionate use of JAK1/2 inhibitor ruxolitinib for severe COVID19: a prospective observational study. Leukemia 35, 1121-1133 (2021). https://doi.org/10.1038/s41375-020-01018-y

Vannucchi AM, Mortara A, D'Alessio A, et al. (2021 b) JAK Inhibition with Ruxolitinib in Patients with COVID-19 and Severe Pneumonia: Multicenter Clinical Experience from a Compassionate Use Program in Italy. J Clin Med. 2021;10(16):3752. https:// doi:https://doi.org/10.3390/jcm10163752

Vasileva D, Badawi A (2019) C-reactive protein as a biomarker of severe H1N1 influenza. Inflamm Res 68(1):39-46. https://doi. org/10.1007/s00011-018-1188-x

Wang C, Horby PW, Hayden FG, Gao GF (2020) A novel coronavirus outbreak of global health concern. Lancet 395:470-473. https:// doi.org/10.1016/s0140-6736(20)30185-9

Wang J-T, Sheng W-H, Fang C-T et al (2004) Clinical manifestations, laboratory findings, and treatment outcomes of SARS patients. Emerg Infect Dis 10(5):818-24

Xu X, Han M, Li T et al (2020a) Effective treatment of severe COVID-19 patients with tocilizumab. Proc Natl Acad Sci U S A 117(20):10970-10975. https://doi.org/10.1073/pnas.2005615117
Xu Z, Shi L, Wang Y et al (2020b) Pathological findings of COVID19 associated with acute respiratory distress syndrome. Lancet Respir Med 8:420-422. https://doi.org/10.1016/s2213-2600(20) 30076-x

Yao XH, Luo T, Shi Y et al (2021) A cohort autopsy study defines COVID-19 systemic pathogenesis. Cell Res 31:836-846. https:// doi.org/10.1038/s41422-021-00523-8

Ye Q, Wang B, Mao J (2020) The pathogenesis and treatment of the 'Cytokine Storm' in COVID-19. J Infect 80:607. https://doi.org/ 10.1016/J.JINF.2020.03.037

Young E (2008) The anti-inflammatory effects of heparin and related compounds. Thromb Res 122:743-752. https://doi.org/10.1016/j. thromres.2006.10.026

Yousefi H, Mashouri L, Okpechi SC et al (2021) Repurposing existing drugs for the treatment of COVID-19/SARS-CoV-2 infection: A review describing drug mechanisms of action. Biochem Pharmacol 183:114296. https://doi.org/10.1016/j.bcp.2020.114296

Publisher's Note Springer Nature remains neutral with regard to jurisdictional claims in published maps and institutional affiliations. 